AM I MY BROTHER'S KEEPER? SIBLING SPILLOVER EFFECTS: THE CASE OF DEVELOPMENTAL DISABILITIES AND EXTERNALIZING BEHAVIOR

\author{
Jason Fletcher \\ Nicole L. Hair \\ Barbara L. Wolfe \\ Working Paper 18279 \\ http://www.nber.org/papers/w18279 \\ NATIONAL BUREAU OF ECONOMIC RESEARCH \\ 1050 Massachusetts Avenue \\ Cambridge, MA 02138 \\ August 2012
}

The authors thank the WT Grant Foundation for their support for this research. Fletcher also thanks the Robert Wood Johnson Foundation Health and Society Scholars Program for financial support. The views expressed herein are those of the authors and do not necessarily reflect the views of the National Bureau of Economic Research.

NBER working papers are circulated for discussion and comment purposes. They have not been peerreviewed or been subject to the review by the NBER Board of Directors that accompanies official NBER publications.

(C) 2012 by Jason Fletcher, Nicole L. Hair, and Barbara L. Wolfe. All rights reserved. Short sections of text, not to exceed two paragraphs, may be quoted without explicit permission provided that full credit, including $(\mathcal{C}$ notice, is given to the source. 
Am I my Brother's Keeper? Sibling Spillover Effects: The Case of Developmental Disabilities and Externalizing Behavior

Jason Fletcher, Nicole L. Hair, and Barbara L. Wolfe

NBER Working Paper No. 18279

August 2012

JEL No. I12,J24

\section{ABSTRACT}

Using a sample of sibling pairs from the PSID-CDS, we examine the effects of sibling health status on early educational outcomes. We find that sibling developmental disability and externalizing behavior ar associated with reductions in math and language achievement Estimated spillovers for developmental disability are large and robust to both a rich set of family-level controls and a fixed effects analysis that exploits the availability of in-sample cousins. Our results suggest the importance of siblings in the determination of children's human capital as well as the potential for typically uncounted benefits to improving children's health through family multiplier effects

Jason Fletcher

Yale School of Public Health

Department of Health Policy and Management

60 College Street, \#303

New Haven, CT 06520

and NBER

jason.fletcher@yale.edu

Nicole L. Hair

Department of Economics

University of Wisconsin-Madison

Madison, WI 53706

nhair@wisc.edu
Barbara L. Wolfe

1225 Observatory Dr

University of Wisconsin

Madison, WI 53706

and NBER

BWolfe@wisc.edu 


\title{
Am I my Brother's Keeper? Sibling Spillover Effects: The Case of Developmental Disabilities and Externalizing Behavior
}

\author{
Jason Fletcher, Nicole Hair, and Barbara Wolfe*
}

July 27,2012

\begin{abstract}
Using a sample of sibling pairs from the PSID-CDS, we examine the effects of sibling health status on early educational outcomes. We find that sibling developmental disability and externalizing behavior are associated with reductions in math and language achievement. Estimated spillovers for developmental disability are large and robust to both a rich set of family-level controls and a fixed effects analysis that exploits the availability of in-sample cousins. Our results suggest the importance of siblings in the determination of children's human capital as well as the potential for typically uncounted benefits to improving children's health through family multiplier effects.
\end{abstract}

\section{Introduction}

While there has been extensive research across the social sciences examining the determinants of child achievement, researchers still do not fully understand how the immediate circumstances faced during childhood affect human capital accumulation. The influence of children's health status on their own educational outcomes (as well as parental decisions and family resources) is well-documented. Much less is known about the direct and indirect

*Fletcher: Yale University. Hair: University of Wisconsin-Madison. Wolfe: University of WisconsinMadison. The authors thank the WT Grant Foundation for their support of this research. Fletcher also acknowledges the Robert Wood Johnson Foundation Health \& Society Scholars program for its financial support. The authors would like to thank Marsha Seltzer for sharing her knowledge of developmental disabilities with them and Donna Nordquist at the PSID help desk. The authors thank participants at a seminar at the Rand Corporation, the 2011 iHEA Conference, the PSID CDS-III and TA New Results Workshop Conference, the 2012 summer health economics workshop in Sydney, a seminar at RSE at Australian National University, and the 2012 ASHE Conference for helpful comments on preliminary presentations of this work. 
effects of children's health status on the outcomes of their siblings. The relative scarcity of large scale research in this area is surprising. The great majority (roughly $80 \%$ ) of children in the United States grow up with siblings (Dunn, 1992). Siblings share a common family heritage, both genetically and experientially, and may take on a number of roles during development: role models, playmates, teachers, friends, and confidants. They share the benefits of their parents' human capital and capital resources (i.e., housing, private transport, and neighborhood), while competing for parental attention and investments (Becker and Lewis, 1973; Rosenzweig and Zhang, 2009).

A sibling's health status may be expected to directly influence children's development in a number of ways. Sociologists have suggested that siblings may exert influence by acting as role models (Haynie and McHugh, 2003). In addition, there is evidence in the psychology literature to suggest that children's personality and intelligence are shaped by direct interactions with their siblings (Arnold, Levine and Patterson, 1975). To the extent that health status influences these interactions, a child's poor health could directly impinge on siblings' outcomes. It is also possible that a child's health problems may affect siblings indirectly. Many childhood conditions have been shown to influence the availability of family financial resources (i.e., through direct medical expenditures or maternal labor supply decisions). Parents may also consider variation in endowments when allocating resources across their children (Becker and Lewis, 1973; Rosenzweig and Zhang, 2009).

This study examines the effects of a sibling's poor health on a set of early educational outcomes intended to capture a child's human capital accumulation. Most related research has been based on small convenience samples ${ }^{1}$ and there are few, if any, studies that use large national datasets to examine sibling health spillovers on global educational outcomes. Our analysis is based on a sample of sibling pairs from the Child Development Supplement

\footnotetext{
${ }^{1}$ For example, Smith et al. (2002) examine a sample of 30 males diagnosed with ADHD and their siblings; Mikami and Pfiffner (2008) examine a sample of 91 children recruited from a university ADHD research clinic; Mash and Johnston (1983) examine a sample of 46 boys to study the effects of ADHD; Derouin and Jessee (1996) examine information from 15 families; Williams et al. (2002) examine 252 siblings of children in poor health; and Greene et al. (2011) examine approximately 500, mostly white children recruited from clinical settings.
} 
of the Panel Study of Income Dynamics (PSID-CDS). The PSID includes extensive information on families over the past 40 years (and across three generations). We investigate the importance of sibling health spillovers using several different estimation strategies, including OLS estimation with a rich set of family-level controls and a fixed effects analysis. Our fixed effects analysis is unique in that it exploits the genealogical design of the PSID in order to use cousins to control for otherwise unobserved family characteristics. Finally, guided by evidence in the psychology literature, we explore heterogeneity in sibling health spillovers according to the child's gender and relative age.

We focus on two childhood chronic conditions: developmental disability and externalizing behavior. These conditions are both common and recently found to be increasing in prevalence. Using data from the National Health Interview Survey, Boyle et al. (2011) report that nearly 10 percent of children have some form of developmental disability, and nearly 7 percent of children have reported ADHD (these diagnoses may overlap). In contrast, "only" 0.58 percent of children have a reported sensory disability, such as blindness or moderate to profound hearing loss. In terms of trends, the study reports marked increases in autism from 1997-99 to 2008-09, along with increases in ADHD, seizures, and other developmental delays over the same time period. These conditions have far-reaching effects on the affected individual. Consequently, having an affected child in the household can be expected to present challenges for the family unit that may lead to spillover effects on siblings (as well as other family members).

We find that chronic conditions during childhood, namely developmental disability and externalizing behavior, may have negative consequences not only for the child directly affected by the condition but also for other children in the household. Specifically, we find that having a sibling with a developmental disability or externalizing behavior is associated with reductions in measured math and language achievement. There is also some evidence to suggest an increased propensity for grade repetition. We find that estimates of sibling health spillovers vary across our conditions of interest, with larger effects estimated in the 
case of developmental disability. We also find evidence that a sibling's poor health may have heterogeneous effects according to particular characteristics of the sibship, with sisters and younger siblings (particularly in the case of externalizing behavior) appearing to fare worse.

\section{Background}

\subsection{Why Would Siblings Affect Human Capital Accumulation?}

When addressing the potential importance of siblings in children's human capital accumulation, three theoretical perspectives from the economics literature are relevant: the quantityquality trade-off in children, parental labor market response, and the intra-household allocation of resources across children. The literature on the quantity-quality trade-off in children (Becker and Lewis, 1973; Rosenzweig and Zhang, 2009) explores the interaction of parents' fertility and child-investment decisions. When making choices about fertility, parents are thought to weigh outcomes of quantity (increased number of children) against quality (human capital of children). Models of the trade-off suggest that as family size increases, there are reductions in average child quality. With a larger number of siblings present, there are likely fewer resources available per child. Parents provide material goods and emotional support to their children, and siblings are then thought to vie for parents' time and attention. This literature typically assumes homogeneity of children within a household. If parents have a child with a significant disability, the quantity-quality trade-off and associated resource constraints may become more complex.

Work in the parental labor market response literature has investigated the effects of having a child with a disability on parental decisions (rather than sibling outcomes). The focus has typically been on either mother's time allocation, i.e. maternal labor force participation (Powers, 2004) or family resources (Parish and Cloud, 2006). In general, the literature has

found small reductions in maternal labor force participation, and hence reductions in family resources. Recent work suggests, however, that the implications of the reported reductions 
in maternal labor market participation on child development may be unclear; there may be fewer material resources available, but perhaps more parental time (Gould, 2004; Burton and Phipps, 2009).

Intra-household resource allocation across children has been a topic of interest since the early work of Becker and Tomes (1976) and Behrman, Pollak and Taubman (1982). Parents are thought to care about the quality (human capital, wealth) of their children in addition to their own consumption. Depending on parental preferences and the human capital technology, parents may optimally exhibit investment strategies that compensate for or reinforce the variation in endowments across their children. An early-life shock to the endowment of one child may therefore alter the parental investments made in all children in the household. ${ }^{2}$

Following the existing literature, we broadly consider a simple framework for a two-child household that fits within the context of the current study (see Appendix A). One sibling is healthy (high endowment), while the other has a disability or chronic health condition (low endowment). Children's human capital is a function of this initial endowment as well as parental investments. Altruistic parents, who care about the quality (human capital) of their children in addition to their own consumption, maximize utility subject to the human capital technology and a budget constraint. Whether parents optimally adopt a reinforcing, compensating, or neutral investment strategy in response to the differences in their children's endowments will hinge on a tension between parental preferences and the human capital production technology, i.e. parental aversion to inequality (Behrman, Pollack, and Taubman, 1982) and the complementarity (substitutability) of endowment and investment in the production of human capital. If parents adopt a compensating strategy, such that

\footnotetext{
${ }^{2}$ There is no consensus in the empirical literature as to whether parents tend to invest in ways that compensate for rather than reinforce variation in endowments across their children. Some studies, particularly those in developing countries, have found evidence of reinforcing investment behaviors(Rosenzweig and Wolpin, 1988; Behrman, Rosenzweig and Taubman, 1994). Other work suggests that parents make compensatory investments (Behrman, Pollak and Taubman, 1982; Pitt, Rosenzweig and Hassan, 1990). In more recent work, Hsin (2013) finds little evidence of a relationship between low birth weight and maternal time investments, but argues that this average effect masks important heterogeneity by socioeconomic status.
} 
more resources are allocated to the low endowment child, the human capital accumulation of the healthy sibling suffers. If, instead, parents adopt a reinforcing strategy, such that more resources are allocated to the high endowment child, the healthy sibling benefits from increased human capital.

The standard framework generally precludes any direct effect of sibling poor health (low endowment) on human capital accumulation. A sibling's early-life health insult may only affect human capital outcomes through the reallocation of intra-household resources. This is a potential concern, particularly in the context where one member of the sibling pair is disabled. In order to accommodate expectations of a direct or social learning effect of a sibling's poor health (Arnold, Levine and Patterson, 1975; Hauser and Wong, 1989; Oettinger, 2000; Smith et al., 2002; Mikami and Pfiffner, 2008), the standard framework may be extended to introduce sibling endowment as an additional factor in the human capital production function (see Appendix A). In this case, the effect on human capital may be decomposed into two channels: the resource reallocation effect and the direct or social learning effect. As before, if parents adopt a compensating strategy, such that more resources are allocated to the low endowment child, the human capital accumulation of the healthy sibling suffers. However, if parents adopt a reinforcing strategy, such that more resources are allocated to the high endowment child, the net effect on the human capital of the healthy child is now ambiguous. The relative magnitudes of the social learning (detrimental) and resource reallocation effect (beneficial) are important.

\subsection{Prior Evidence on the Effects of Siblings on Children's Out- comes}

While it has been well documented that children's health status and behaviors impact their own educational outcomes as well as parental decisions and family resources, much less is known about the direct and indirect effects of children's health on their siblings' outcomes.

Within the economics literature, there is some existing evidence of sibling influences from 
an older sibling to a younger sibling, including high school graduation status (Oettinger, 2000), tobacco, alcohol, and marijuana use (Ouyang, 2004), and the initiation of sexual intercourse (Widmer, 1997). Beyond this, there is some research that is suggestive of the importance of siblings, including the literature that finds that family size (Hanushek, 1992), birth order (Behrman and Taubman, 1986), and sex composition of sibship (Butcher and Case, 1994; Kaestner, 1997) all help to shape achievement in children. The large literature providing evidence that peers influence achievement and health behaviors is also suggestive that siblings may also exert a strong influence (Hanushek and Rivkin, 2003; Gaviria and Raphael, 2001).

Most past research on the siblings of individuals with developmental disabilities is from the psychology literature. This work tends to focus on emotional and adjustment outcomes of the sibling pair during childhood (Rossiter and Sharpe, 2001; Sharpe and Rossiter, 2002; Stoneman, 1998; Stoneman and Brody, 1993). In reviewing this research, Stoneman (2001, 2005 ) concluded that there are high levels of interaction when one sibling has a developmental disability (DD), especially during childhood, although some of this interaction is likely due to the expanded childcare roles that non-disabled siblings, especially sisters, often play. A metaanalytic review of the effects on the sibling relationship and sibling well-being came to a more negative conclusion (Rossiter and Sharpe, 2001). Based on 25 studies of siblings of individuals with DD, Rossiter and Sharpe concluded that there was a statistically significant but small negative effect on the psychological functioning of these siblings (depression, anxiety, and behavioral adjustment in terms of internalizing and externalizing behaviors). Rossiter and Sharpe (2001) show that well children with siblings with chronic or severe health conditions may be disadvantaged because their parents' attention is diverted to the siblings with an illness, their siblings with a condition exhibit impaired interactions, other children ostracize and isolate all the children in this family, and because of the direct caretaking responsibilities of having an unhealthy sibling.

In related research, children with siblings with ADHD have been shown to experience 
higher negative relationships within the family as symptoms increase (Smith et al., 2002; Mikami and Pfiffner, 2008), younger siblings mimic the bad behaviors of their older siblings with ADHD (Arnold, Levine and Patterson, 1975), and have higher risks of substance use disorders (Milberger et al., 1997). Well children with siblings with mental retardation have lower psychological functioning, including higher rates of depression and anxiety (Rossiter and Sharpe, 2001). In more recent work, Fletcher and Wolfe (2008) explore the possible influence of having a sibling with ADHD on adolescents. They find significant negative effects of having a sibling with ADHD on three different measures of years of schooling as well as the probability of being suspended. In terms of measures of schooling, they estimate a larger influence of ADHD on siblings than on the individual with ADHD for years of school and the probability of attending college but not for other measures, some of which (GPA and grade repetition) are only significant for the individual with ADHD.

\section{Data}

Our analysis is based on data from the Panel Study of Income Dynamics (PSID) and its Child Development Supplement (PSID-CDS). The PSID is a longitudinal study that began in 1968 with a core sample of approximately 4,800 families. The core PSID survey includes data covering employment, income, wealth, education, health, marriage and fertility histories, and numerous other topics. The study has a genealogical-based design. As children of sample families establish households of their own, they and all the members of their new household continue to be followed as sample members. As a result of this rather unique design, the dataset contains information about multiple generations of a family. In many cases, as 1968 PSID children have now started families of their own, it is possible to trace families across three generations and access extensive background information collected from these families over the past 40 years.

The Child Development Supplement was introduced in 1997 to collect additional infor- 
mation for a subset of PSID children (ages 0-12 years in 1997) and includes an array of measures tied to the development of children across the domains of health, psychological well-being, social relationships, cognitive development, and education. Sample children have been followed over a period of ten years, with subsequent rounds of the CDS administered in 2002 and 2007. The PSID-CDS sample currently contains approximately 8,000 observations on 5,500 children from 2,400 families. The survey sampled up to two children per family unit, ${ }^{3}$ and our analysis will focus on the approximately 1,100 CDS sibling pairs. ${ }^{4}$ The sibling sample, combining observations from the supplement's three waves, contains approximately 5,000 observations on children ranging in age from 0 to 18 years.

As part of our analysis, we estimate fixed effects models in order to control for otherwise unobserved family characteristics. As our sibling sample described above consists solely of sibling pairs and we are interested in chronic health conditions that do not vary with time, sibling-level fixed effects would be perfectly collinear with own and sibling health status. Our fixed effects analysis exploits the unique genealogical design of the PSID. Nearly 90 percent of children in the sibling sample are members of long-term PSID families and represent a third generation of PSID participation. In these cases, it may be possible to identify extended family members, or cousins, in the CDS sample by tracing sample children back to their original 1968 PSID household. Just under half (43.8\%) of children in the sibling sample have in-sample cousins. The extended families range in size from two unique sibling pairs $(59 \%$ of extended families) to, in one instance, five unique sibling pairs. Combining observations from the supplement's three waves, the cousin sample includes 2,723 observations on 982 children from 209 distinct extended families.

The remaining 10 percent of children in the sibling sample are drawn from family units

\footnotetext{
${ }^{3}$ The PSID-CDS surveyed a maximum of two children per family unit, so it is possible for a child in our sibling sample to have additional siblings not captured in the CDS sample. To the extent that there are unobserved children in poor health in these households, our estimates may be biased downward. We test the sensitivity of our results to restricting our sample to only those families reporting fewer than three children (around half of our sibling sample) and find our estimates to be robust (Table 5).

${ }^{4}$ Siblings were identified using the PSID's FIMS map file. All sibling types (full, step, adopted) were permitted, but the sample was restricted to those sibling pairs identified as residing in the same family unit
} 
newly added to the PSID through the immigrant refresher sample in $1997 .{ }^{5}$ These children do not have the same family history available as those children descended from original 1968 families. While these children represent only a small fraction of the overall sibling sample, they represent over 85 percent of the Hispanic children and over 97 percent of the children reporting Asian or Pacific Islander background. This change in composition from our sibling sample to our cousin sample is a potential limitation of our cousin-based fixed effect analysis. However, we test the sensitivity of our baseline estimates (sibling sample) to the exclusion of children in these groups and find that our results are not sensitive to the sample restriction (Table 5).

Table 1 provides a comparison of the full PSID-CDS sample to our sibling sample, as well as to the subsample of siblings who also have extended family members in the sample (CDS cousins). The sample means presented in Table 1 suggest that our sibling sample is highly comparable to the full PSID-CDS in terms of observable demographic and socioeconomic characteristics. We find no concerning differences in terms of age, gender, race, primary caregiver education, income, or parental socioeconomic backgrounds. The average family size is slightly larger in households with CDS siblings, but this may be expected given the nature of the sample. A comparison of CDS siblings to the subsample of siblings with CDS cousins shows the samples to be comparable with the exception of racial composition as mentioned earlier.

\subsection{Measures of Human Capital}

We focus on a set of early education outcomes that are intended to capture a child's human capital accumulation. These measures include grade repetition and children's scores on three sections of the Woodcock-Johnson Revised (WJ-R) tests of achievement: Applied Problems, Letter-Word, and Passage Comprehension. The WJ-R tests are standardized educational

\footnotetext{
${ }^{5}$ The immigrant refresher sample introduced recent (post-1968) immigrant families and their children to the PSID sample in order to reflect changes in the composition of the U.S. national population. These recent immigrants were not previously represented in the PSID.
} 
achievement assessments and are designed to provide a normative score that shows the child's language and math abilities in comparison to a national average for the child's age. ${ }^{6}$ Children aged 3 years and older were eligible to complete the Applied Problems and LetterWord tests. The Passage Comprehension test was administered to older children who were at least 6 years of age. ${ }^{7}$

Panel B of Table 1 provides a comparison of our measures of human capital accumulation across the full PSID-CDS sample and our CDS siblings and cousins samples. Close to $11 \%$ of our CDS siblings sample has ever repeated a grade. Grade repetition is more common among males $(14.7 \%)$ than females $(7.7 \%)$. The average scores on all three sections of the WJ-R tests of achievement are slightly above national norms. This holds true in the full PSID-CDS as well as in our CDS siblings and cousins samples. Males score slightly higher on the WJ-R Applied Problems test, while females tend to score higher on the Letter-Word and Passage Comprehension tests.

\subsection{Indicators of Poor Health}

As part of the CDS interview, primary caregivers are asked a series of questions assessing the sample child's health status, including a global measure of health and diagnosis of chronic conditions. In addition, the CDS includes the Behavior Problems Index (BPI) ${ }^{8}$ to assess the incidence and severity of behavioral problems in children. The BPI divides problem behaviors into two subscales: a measure of externalizing or aggressive behavior ${ }^{9}$ and a measure of

\footnotetext{
${ }^{6}$ Scores on the WJ-R are standardized with a mean of 100 and standard deviation of 15 .

${ }^{7}$ In a small number of cases where that was a severe disability (e.g., co-morbid autism and mental retardation), a child may not have been able to complete the assessments. Interviewers deferred to the judgement of the primary caregiver. This may bias downward estimates of the effect of own disability, but should not affect estimates of sibling spillovers. These sibling pairs are not excluded from the regression sample when the health sibling is the target child.

${ }^{8}$ The Behavior Problem Index was developed by James Peterson and Nicholas Zill from the Achenbach Behavior Problems Checklist to measure in a survey setting the incidence and severity of child behavior problems.

${ }^{9}$ In the case of the externalizing subscale, these problem behaviors include: sudden changes in mood or feelings; difficulty concentrating/cannot pay attention for long; bullies or is cruel or mean to others; disobedient; does not seem to feel sorry after misbehavior; trouble getting along with people his/her own age; impulsive or acts without thinking; restless or overly active, cannot sit still; stubborn, sullen, or irritable;
} 
internalizing, withdrawn or sad behavior.

As noted above, our analysis of sibling health spillovers will focus alternately on developmental disability and externalizing behavior as an indicator of health status. ${ }^{10}$ These conditions are both common and expected to have far-reaching effects on the educational and social outcomes of the affected individual. As a result, having an affected child in the household is expected to present challenges for the family unit that may lead to spillover effects on siblings (as well as other members of the family). Developmental disability is perhaps the most studied of children's chronic conditions. Consistent with federal definitions of developmental disability, we classify a sample child as developmentally disabled if he/she has ever been diagnosed with epilepsy, ${ }^{11}$ autism, or mental retardation. These conditions are generally diagnosed in the first few years of life, so a child is likely to be influenced from a time very close to the sibling's birth (or their own birth in the case of younger siblings). According to recent work by Eget (2009)

Growing up in a family of a student with a developmental disability, specifically mental retardation, autism, and those consistent with significant mental limitations, can be a challenging experience. Siblings of these students are often faced with more responsibilities, and sacrifices, and may have less attention given to them because of their sibling's needs. ${ }^{12}$

has a very strong temper and loses it easily; breaks things on purpose or deliberately destroys his/her own or another's things; demands a lot of attention

${ }^{10}$ We had considered sensory deficit (i.e., difficulty hearing/deafness or difficulty seeing/blindness) as an additional disability of potential interest. We did not find statistically significant effects on measures in our set of early educational outcomes, and the results are not presented here. We do not include medical conditions such as asthma and allergies in our analysis. These conditions may present symptoms over quite a broad range of severity. As a result they are not well-defined in terms of the expected limitations experienced by the affected individual (or the resulting challenges faced by the family).

${ }^{11}$ While children with epilepsy/seizure disorder generally have normal intelligence, they are at increased risk for mental health and developmental comorbidities, increasing the need for care coordination and specialized services. In a nationally representative sample, they were found to have a greater risk of limitation in ability to do things, repeating a school grade, poorer social competence and greater parent aggravation (SA, K and N, 2012).

${ }^{12}$ Eget cites the following as the basis of the above quote: Bischoff and Tingstrom (1991); Breslau, Weitzman and Messenger (1981); Dellve, Cernerud and \& Hallberg (2000); Dodd (2004); Opperman and Alant (2003); Pilowsky et al. (2004). 
In recent years, there has been increasing attention paid to externalizing behavior as it is a primary symptom of ADHD. Our measure of externalizing behavior is based on the sample child's score on the externalizing subscale of the BPI. We classify a child as having an externalizing behavior problem if his/her score, averaged over the sample period, is at or above the 90th percentile ${ }^{13}$ of the externalizing subscale distribution (a score of 11 our of a maximum of 17). ${ }^{14}$ We average a child's BPI score over all available periods in order to best identify those children with chronic behavioral problems. ${ }^{15}$

Panel C of Table 1 shows the incidence of chronic health conditions in our CDS siblings and cousins samples as well as in the full PSID-CDS. By construction, approximately 10 percent of our sample children are classified as having an externalizing behavior problem. Developmental disabilities are less common, with $4.5 \%$ of sample children affected by at least one developmental disability. Among CDS siblings with a developmental disability, epilepsy is the most common qualifying condition. Comorbidity is common. In our sample, 17 percent of children with DD report multiple qualifying disabilities (Table B.1). There are some differences in the distribution of disabilities according to gender. As may be expected, autism is found to be more prevalent in males than females (37.8\% of DD cases versus $15.1 \%$ ).

Tables AB.2 and AB.3 offer insight into individual comorbidity and within-family correlation of chronic conditions, respectively. Developmental disability is positively but modestly correlated between siblings $(\rho=0.066)$. The correlation between sibling externalizing behavior is somewhat stronger $(\rho=0.149)$. Children with an externalizing sibling also have

\footnotetext{
${ }^{13}$ We test the sensitivity of our results to our selection of the 90th percentile as the threshold for externalizing behavior. Our results are robust to lowering the threshold to the 85th and 80th percentiles (Table $5)$.

${ }^{14}$ Currie and Stabile (2006) use a similar approach in their work with ADHD. They argue that it is problematic to focus only on those with diagnosed ADHD as there can be systematic differences in those children for whom treatment has been sought and for those whom it has not. Our approaches differ in the particular scales used. In our work, we use the 17-item externalizing subscale of the PSID-CDS BPI. In their work, Currie and Stabile use the 5-item hyperactivity subscale of the NLSY BPI. In our sample, children with diagnosed ADHD score one standard deviation higher at the mean compared to the full PSID-CDS sample (Table B.4).

${ }^{15}$ In our sample, $88.5 \%$ of observations were consistently identified as "externalizing" /" non-externalizing" across permanent and transitory measures. We test the sensitivity of our results to the use of contemporaneous (versus averaged) BPI score in classifying children with externalizing behavior (Table 5).
} 
slightly elevated BPI scores (Table B.4). ${ }^{16}$ Neither developmental disability nor externalizing behavior appears to be concentrated within extended families.

\subsection{Predictors of Poor Health}

The aim of our study is to examine the potential spillover effects of a sibling's poor health on outcomes tied to human capital accumulation. An important alternative hypothesis for these associations is that they are driven by confounding family factors; households with a child in poor health may differ systematically from households with healthy children. These (potentially unobservable) differences in households may bias our estimation of sibling health spillover effects. In order to explore the potential importance of this issue, we examine the observable family correlates of having a child in poor health using the PSID-CDS sample.

Table 2 shows the results of an analysis attempting to predict the presence of a child with a developmental disability. We utilize a set of factors that predate the birth of the child in order to focus on exogenous determinants. We find some racial differences, where black families are nearly 2 percentage points less likely to have a child in the household with a developmental disability. We also find some evidence that the likelihood of having a child with a developmental disability is negatively associated with maternal education, since high school dropout mothers are 3 to 4 percentage points more likely to have this outcome. On the other hand, many family and individual factors are unrelated to this outcome, including socioeconomic status of the father during childhood and age of the mother at birth. Table 3 then shows the results of a similar analysis for the presence of a child with externalizing behavior, and we find even fewer associations with family factors. The only statistically significant difference across families is the educational level of the mother.

These findings of the predictors of the presence of an unhealthy child in a household necessitate the use of controls for observable differences across families. Following the logic

\footnotetext{
${ }^{16}$ We test the sensitivity of our results to a control for own BPI score (rather than an indicator for own externalizing behavior). The magnitude of the coefficients of interest are slightly reduced, but our results are largely robust (Table 5).
} 
of Altonji, Elder and Taber (2005), among others, we suggest that if the estimated effects of sibling health spillovers are robust to the inclusion of important observable factors in our data, any residual effects of unobservables is likely to be small. However, there may be additional unobserved differences in families with and without a child that is DD or exhibits externalizing behaviors including genetic differences. We utilize the unique genealogical structure of our data to deploy cousin fixed effects specifications to explore this possibility.

\section{Empirical Methods}

To obtain baseline estimates of the effects of sibling poor health on children's human capital accumulation, we follow Fletcher and Wolfe (2008) and begin with OLS models of the following form:

$$
Y_{i t}=\beta+\beta_{1} \text { Health }_{j}+\beta_{2} \text { Health }_{i}+\beta_{3} X_{i t}+\delta_{t}+\epsilon_{i t}
$$

where $Y_{i t}$ is one of the early educational outcomes for child i in period t. Health $h_{j}$ is a measure of the sibling's health status. Depending on the specified health condition of interest, this measure is either an indicator for a sibling's developmental disability or a sibling's externalizing behavior. Health $h_{i}$ is similarly defined, but is an indicator for a child's own health status. $X_{i t}$ is a vector of individual- and family-level covariates. Our models allow for separate intercepts for the three waves of the PSID-CDS, and all standard errors are clustered at the family (sibling pair) level.

We estimate equation (1) using three different versions of $X_{i t}$. The first version includes child age, child gender, child race, birth order, an indicator of high-risk birth (mother's age at birth $<20$ years or $\geq 40$ years), and maternal education (less than high school, high school, or more than high school). The second version of $X_{i t}$ is a much fuller list of controls. In addition to the measures listed above, it also includes: mother's marital status at time of first birth; urbanicity at time of birth (urban, non-urban); parental family 
background (mother grew up "poor", father grew up "poor"); average family income over five years prior to the birth of first child; parental history of childhood psychological or emotional problems; primary caregiver's religion (Catholic, Protestant, no religion, other religions); parent(s) ever incarcerated; father's interview status (active PSID member, nonsample/non-response); and whether the child's family recently immigrated to the United States (PSID immigrant refresher family). The third version of $X_{i t}$ instead introduces a set of potentially endogenous mediators: family income (five-year rolling average of total family income),${ }^{17}$ family size (number of persons in the family unit), and family structure (whether both biological parents in household).

In each case, we attempt to carefully define our comparison or control group. The PSIDCDS sample includes children with a range of health conditions. However, for many of these conditions, the incidence within our sample is too low to address them directly in our analysis. We restrict our focus to two specific conditions of interest: developmental disability and externalizing behavior. For each of these conditions of interest, we restrict the regression sample such that a sibling pair is included in the sample only if (at least) one of the following conditions is satisfied: ${ }^{18}$ the target child has the specified health condition, the child's sibling has the specified health condition, or both members of the sibling pair are healthy. A child is classified as "healthy" if he/she is free of a set of health conditions we observe in the CDS, including developmental disability, externalizing behavior, developmental delay (including speech impairment), serious hearing difficulty or deafness, and serious difficulty seeing or blindness.

We next estimate fixed effects models using cousins. As our sample consists solely of sibling pairs and we are interested in chronic health conditions that do not vary with time,

\footnotetext{
${ }^{17}$ We tested the sensitivity of our results to alternative measures of family income, including contemporaneous income, average income in five years prior to child's birth, average income in five years prior to mother's first birth, and income adjusted for family size

${ }^{18} \mathrm{~A}$ sibling pair will be included in the regression sample if both the target child and his/her sibling have the condition of interest. A sibling pair may also be included in the regression sample if one sibling has the condition of interest and the other sibling is "unhealthy", i.e. has a chronic condition other than the condition of interest.
} 
we are not able to introduce sibling-level fixed effects to our specifications. Using the subsample of sibling pairs who also have extended family members (CDS cousins) in the sample, however, we estimate fixed effects models of the form:

$$
Y_{i t}=\beta+\beta_{1} \text { Health }_{j}+\beta_{2} \text { Health }_{i}+\beta_{3} X_{i t}+\delta_{t}+\alpha_{E}+\epsilon_{i t}
$$

where $\alpha_{E}$ is a set of binary indicators for each extended family (or set of cousins). $X_{i t}$ is a vector of individual and immediate family-level controls that includes child age, child gender, child birth order, child high-risk birth, and maternal education. There was too little variation of reported race within extended families to include child race in $X_{i t}$. By including extended family or cousin fixed effects, we control for otherwise unobservable time-invariant characteristics consistent across units in the extended family, including shared genetics and common grandparent's SES and culture, diet and norms.

For the cousin fixed effects analysis, we adjust our definition of the control or comparison group to reflect the increased scale of the family structure of interest. For each of our conditions of interest, we restrict the regression sample such that all members of an extended family are included in the sample if any member of the extended family has the specified health condition or if all members of the extended family are healthy. An additional adjustment was made for large extended families (i.e. families for which we observe cousins from more than two family units) with an unhealthy member(s), but no history of the condition of interest. In these cases, if at least two family units within the extended family had healthy sibling pairs, the healthy sibling pairs from that extended family were included in the comparison group. 


\section{Results}

Table 4 shows OLS estimates for the effects of sibling poor health, ${ }^{19}$ specifically developmental disability (Panel A) and externalizing behavior (Panel B), on our measures of human capital accumulation with varying sets of controls. The first column shows estimates with the baseline set of controls, the second column shows estimates with a rich set of controls for family background, and the third column shows estimates with a set of potentially endogenous family mediators: family income, family size, and family structure.

Our baseline results suggest that chronic conditions during childhood have detrimental effects not only on the early educational outcomes of the child directly affected but also on the human capital accumulation of other children in the household. We find evidence that having a sibling in poor health, either a sibling with developmental disability or a sibling with externalizing behavior, may be associated with an increased risk of ever having repeated a grade. In the case of externalizing behavior, we find that a sibling's poor health is associated with lower scores on the Woodcock-Johnson (WJ-R) Applied Problems, Letter-Word, and Passage Comprehension tests. We estimate even larger sibling health spillovers on measured math and language achievement in the case of developmental disability. In particular, our results suggest that children with a developmentally disabled sibling may be expected to score 3.8 (Passage Comprehension) to 5.8 (Letter-Word) points lower on the WJ-R achievement tests. Score reductions of this magnitude represent $1 / 4$ to $1 / 3$ of a standard deviation. The inclusion of a rich set of controls for family background (Column 2) has very little effect on the estimated effects of sibling health spillovers.

The specifications in Columns 1 and 2 estimate an "overall" effect of sibling poor health on measures of human capital accumulation. These specifications do not control for potentially endogenous mediators. Prior research suggests that a child's poor health may affect the financial resources, fertility decisions, and structure of households. That is, if a family has

\footnotetext{
${ }^{19}$ In the case of grade repetition, a binary outcome measure, we estimate a linear probability model; however, our results are robust to probit estimation (Table 5).
} 
a child with a developmental disability or externalizing behavior, parents may reduce labor force participation in order to care for the child and thus have reduced incomes. Similarly, the stress associated with raising a child with one of these conditions may lead to parental separation or divorce as well as influence parents' desired (and actual) number of children. It is possible that children's responses to a sibling's developmental disability or externalizing behavior may be the result of effects on family income, family size, and family structure. We begin to explore these mediators with our estimates in Column 3. As one might expect, the point estimates for the effect of a sibling's poor health are reduced, suggesting a role for family income, family size, and family structure. Point estimates of sibling health spillovers are reduced by an average of $18 \%$ and $9 \%$ in the case of externalizing behavior and developmental disability, respectively. Qualitatively, our core results are unchanged.

The coefficients on the other control variables are generally consistent with expectations from the related literatures. ${ }^{20}$ For example, the higher education of a child's mother or primary caregiver is highly predictive of improved outcomes across all four of our measures of human capital accumulation. Children of mothers who were living in urban areas or married at the time of their first birth tend to outperform their peers. In addition, the achievement gap is reflected in significantly worse outcomes associated with a child's minority status.

Even with controls for a rich set of observable family characteristics, it is still possible that families with a child with a developmental disability or externalizing behavior may differ from families with healthy children in many unobserved ways. By introducing extended family or cousin fixed effects, we are able to control for unobserved time-invariant family characteristics that may bias our OLS estimates. These characteristics might include shared genetics and common grandparent's SES and culture, diet and norms.

Table 6 shows fixed effects estimates for the influence of sibling poor health on our measures of child human capital accumulation. Once we adjust for time-invariant unobserved family characteristics, the results suggest that there may not be a significant influence of

\footnotetext{
${ }^{20}$ In the interest of economizing on space, we present point estimates only for our coefficients of interest. Tables with a full set of coefficients are available upon request.
} 
sibling externalizing behavior on these outcomes (Panel B). We find that the estimated effect diminishes in magnitude across all four of our outcome measures when compared to our OLS estimates. None of the estimates are statistically significant at conventional levels.

The estimates for the effects of sibling developmental disability (Panel A), however, are largely robust to the inclusion of extended family fixed effects. Having a sibling with a developmental disability is associated with important reductions in measured language and math achievement. On average, a child with a developmentally disabled sibling may be expected to score four to six points, or $1 / 3$ of a standard deviation, ${ }^{21}$ lower on WoodcockJohnson (WJ-R) tests of achievement when compared to children with healthy siblings. These findings suggest a very strong influence of having a sibling with a developmental disability on one's own human capital.

\section{$6 \quad$ Results by Characteristics of Sibship}

Up to this point in our analysis, we have implicitly assumed that a sibling's poor health affects all children equally. However, research in the psychology literature might lead us to expect heterogeneity in sibling spillovers according to specific characteristics of the sibship. Prior evidence suggests that females experience greater intimacy in the sibling relationship compared to males. We may therefore expect that a sibling's poor health may have an increased influence among sisters. In addition, we might expect younger siblings to be especially vulnerable to sibling health spillovers. A child born into a household facing the stresses tied to an older sibling's chronic condition may experience reduced investments and parental attention from the earliest years of life. Additionally, older children often serve as role models and therefore may exert a greater influence on their siblings. Over-identification, where a child may adopt some of the behaviors of a disabled sibling, is more likely to occur if the typically-developing child is younger than the affected sibling (Meyer and Vadasy, 2007). Children born right after a sibling with a disability may feel additional parental pressure to

\footnotetext{
${ }^{21}$ Scores on the WJ-R assessments are standardized with a mean of 100 and standard deviation of 15
} 
achieve. While some children will have the intellectual capacity and personality to live up to these elevated expectations, for other children the additional demands may be too much emotionally or intellectually (Siegel and Silverstein, 1994).

The results of an examination of potential heterogeneity in sibling health spillovers by the child's gender and relative age are presented in Table 7 . The results suggest that when children's human capital accumulation is measured through Woodcock-Johnson assessments, females are more negatively affected by a sibling's poor health. This disparity is especially pronounced in the case of developmental disability. Among females, having a developmentally disabled sibling is associated with significant (on the order of $1 / 3$ to $1 / 2$ of a standard deviation) reductions in measured math and language ability. These large effects are not seen among males. While some of the gender-based differences are imprecisely estimated (only the difference in WJ-R Applied Problems scores is significant at conventional levels), the estimated effect sizes are large across all three sections of the Woodcock-Johnson.

We then divide the sample according to the child's relative age. The "older" group includes those children who were born prior to their sample sibling. The results of Panel B suggest that in the case of externalizing behavior, younger siblings tend to be more negatively affected by a sibling's poor health. Among siblings of a child with externalizing behavior, younger siblings can be expected on average to score 3 to 5 points (or $1 / 5$ to $1 / 3$ of a standard deviation) lower on Woodcock-Johnson tests when compared to children born prior to their affected sibling. In the case of developmental disability, the results are less clear. There is some evidence to suggest that younger siblings may fare worse in terms of grade repetition and performance on the WJ-R Passage Comprehension test, but this pattern is not consistent across the remaining WJ-R measures. 


\section{Discussion and Conclusions}

Although there is high-quality research examining how the immediate circumstances faced during childhood may affect child development and achievement, the influence of siblings remains an area of relatively limited large scale research. With this study, we have begun to address this gap by analyzing one particular aspect of the sibling relationship: the influence of sibling health status on children's human capital accumulation.

We show that childhood chronic health conditions, specifically developmental disability and externalizing behavior, not only negatively affect the early educational outcomes of the individual directly affected but may also influence the human capital accumulation of other children in the household. We find that having a sibling with a developmental disability or externalizing behavior is associated with reductions in measured math and language achievement. There is also some evidence to suggest an increased risk of grade repetition. Estimated sibling health spillovers for developmental disability, in particular, are large. We find that, on average, siblings of children with a developmental disability may be expected to score roughly $1 / 3$ of a standard deviation lower on WJ-R tests of achievement. These results are robust to our attempts to control for potentially confounding family factors.

We also show, consistent with the psychology literature, that the influence of siblings may vary according to characteristics of the sibship. We find evidence of heterogeneity in sibling health spillovers according to the child's gender and relative age. Specifically, when human capital accumulation is measured through WJ-R assessments, sisters appear to be more negatively affected by a sibling's poor health. This gender-based heterogeneity is especially pronounced among siblings of children with developmental disability. In the case of externalizing behavior, we also find evidence of heterogeneous spillovers by the child's relative age, with the human capital accumulation of younger siblings more negatively influenced by a sibling's behavioral problems.

A potential concern with our analysis is that estimates of sibling health spillovers may be biased due to confounding family factors. Families with an unhealthy child may differ from 
families with healthy children along many observed and unobserved dimensions. We explore the potential importance of this issue by examining the observable family correlates of having a child affected by each of our conditions of interest. We find that many observed family and individual characteristics are unrelated to having a child with a developmental disability or externalizing behavior. Nevertheless, there may be additional unobserved differences between families with and without a child in poor health, including genetics. This is an area where our data poses some limitations on the potential analyses. We are unable to conduct a sibling-level fixed effects analysis; our sample consists solely of sibling pairs and we are interested in chronic conditions that do not vary with time. In our analysis we take a unique approach to this issue. We exploit the genealogical design of the PSID in order to construct extended family, or cousin, fixed effects. One caveat to this fixed effects approach, however, is that we are only able to control for unobserved factors on one side of a child's family.

Overall, our results suggest an important influence of sibling health status on children's early educational outcomes. Our analysis of the PSID-CDS sample, however, does not allow us to comment as to whether there may be longer term effects. Future work should consider whether sibling health status influences human capital accumulation, along with associated socioeconomic outcomes, into young adulthood and beyond. Further, future work should explore the potential mechanisms that could explain the link between sibling health and children's outcomes. Potential pathways of interest include (1) direct effects of having a sibling with an illness, such as behavioral spillovers that interfere with the well child's development, (2) income effects, i.e. those due to the need to finance medical expenditures or a parent's reduction in labor force participation, that stem from the sibling's illness and may then spillover onto the well child, and (3) substitution effects, such as those stemming from parents' efforts to either reinforce or offset differences in the health endowments of their children, that could affect the level of time and financial investments made in the well child.

Our results have several important implications. First, they suggest a need to broaden theoretical and empirical models of human capital determinants to include a wider set of 
family factors with an emphasis on the importance of siblings. Second, the results suggest there may be uncounted benefits of improving the health of children on the outcomes of their family members. For example, reducing the hyperactive symptoms of a child through medication or behavioral therapy can benefit the outcomes of the treated child, as well as the child's family members, especially siblings. The magnitude of these spillovers are large and complement other results in the literature suggesting spillovers in addressing poor health in children on their classmates' school performance (Aizer, 2008; Fletcher, 2010). These spillover effects are not currently included as a part of cost-benefit calculations when evaluating programs that aim to improve children's health, but our results combined with others in the literature suggest current calculations of the effects of health improving programs are (potentially severely) underestimated. 


\section{References}

Aizer, Anna. 2008. "Peer Effects and Human Capital Accumulation: the Externalities of ADD." NBER Working Paper No. 14354.

Altonji, Joseph G., Todd E. Elder, and Christopher R. Taber. 2005. "Selection on Observed and Unobserved Variables: Assessing the Effectiveness of Catholic Schools." Journal of Political Economy, 113(1): 151-184.

Arnold, J. E., A. G Levine, and J. R Patterson. 1975. "Changes in sibling behavior following family intervention." Journal of Consulting and Clinical Psychology, 43: 683-688.

Becker, Gary S., and H. Gregg Lewis. 1973. "On the Interaction between the Quantity and Quality of Children." Journal of Political Economy, 81(2): S279-S288.

Becker, Gary S, and Nigel Tomes. 1976. "Child Endowments and the Quantity and Quality of Children." Journal of Political Economy, 84(4): S143-62.

Behrman, Jere R., and Paul Taubman. 1986. "Birth order, schooling, and earnings." Journal of Labor Economics, 4: S121-45.

Behrman, Jere R, Mark R Rosenzweig, and Paul Taubman. 1994. "Endowments and the Allocation of Schooling in the Family and in the Marriage Market: The Twins Experiment." Journal of Political Economy, 102(6): 1131-74.

Behrman, Jere R, Robert A Pollak, and Paul Taubman. 1982. "Parental Preferences and Provision for Progeny." Journal of Political Economy, 90(1): 52-73.

Bischoff, L. B., and D. H Tingstrom. 1991. "Siblings of children with disabilities:Psychological and behavioral characteristics." Counseling Psychology Quarterly, 4(4): $311-322$.

Boyle, Coleen A., Sheree Boulet, Laura A. Schieve, Robin A. Cohen, Stephen J. Blumberg, Marshalyn Yeargin-Allsopp, Susanna Visser, and Michael D. Kogan. 2011. "Trends in the Prevalence of Developmental Disabilities in US Children, 19972008." Pediatrics, 127(6): 1034-1042.

Breslau, N., M. Weitzman, and K. Messenger. 1981. "Psychologic functioning of siblings of disabled children." Pediatrics, 67(3): 344-353.

Burton, P., and S. Phipps. 2009. "Economic Costs of Caring for Children with Disabilities." Journal of Political Economy, 81(2): S279S288.

Butcher, Kristin E., and Anne Case. 1994. "The effect of sibling sex composition on women's education and earnings." Quarterly Journal of Economics, 109: 531-63.

Currie, Janet, and Mark Stabile. 2006. "Child mental health and human capital accumulation: The case of ADHD." Journal of Health Economics, 25(6): 1094 - 1118. 
Dellve, L, L. Cernerud, and L.R. \& Hallberg. 2000. "Harmonizing dilemmas. Siblings of children with DAMP and Asperger syndromes experiences of coping with their life situations." Scandinavian Journal of Caring Science, 14(3): 172-178.

Derouin, D., and P. O. Jessee. 1996. "Impact of a chronic illness in childhood: siblings' perceptions." Issues in Comprehensive Pediatric Nursing, 19(2): 135-147.

Dodd, L. W. 2004. "Supporting the siblings of young children with disabilities." British Journal of Special Education, 21(1): 41-49.

Dunn, J. 1992. "Siblings and development." Current Directions in Psychological Science, 1(1): 6-9.

Eget, Leslie. 2009. "Siblings of those with developmental disabilities: career exploration and likelihood of choosing a helping profession." PhD diss. Indiana University of Pennsylvania.

Fletcher, J. 2010. "Spillover effects of inclusion of classmates with emotional problems on test scores in early elementary school." Journal of Policy Analysis and Management, 29(1): 69-83.

Fletcher, Jason, and Barbara Wolfe. 2008. "Child mental health and human capital accumulation: The case of ADHD revisited." Journal of Health Economics, 27(3): $794-$ 800.

Gaviria, Alejandro, and Steven Raphael. 2001. "School-Based peer effects and juvenile behavior." Review of Economics and Statistics, 83(2): 257-268.

Gould, Elise. 2004. "Decomposing the effects of children's health on mother's labor supply: is it time or money?" Health Economics, 13(6): 525-541.

Greene, Ross W. Ph.D.and Biederman, Joseph M.D, Michael C. B.A. Faraone, Stephen V. Ph.D.and Monuteaux, Eric Sci.D. Mick, Emily P. B.A. DuPre, Catherine S. B.A. Fine, and Jennifer C. B.A. Goring. 2011. "Social Impairment in Girls With ADHD: Patterns, Gender Comparisons, and Correlates." Journal of the American Academy of Child 83 Adolescent Psychiatry, 40(6): 704-710.

Hanushek, Eric A. 1992. "The trade-off between child quantity and quality." Journal of Political Economy, 100: 84-117.

Hanushek, Eric A., Kain John F. Markman Jacob M., and Steven G. Rivkin. 2003. "Does peer ability affect student achievement?" Journal of Applied Econometrics, 18(5): 527-544.

Hauser, R.M., and R. Wong. 1989. "Sibling Resemblance and Inter-Sibling Effects in Educational Attainment." Sociology of Education, 62: 149-71.

Haynie, Dana L., and Suzanne McHugh. 2003. "Sibling deviance: In the shadows of mutual and unique friendship effects?" Criminology, 41(2): 35592. 
Hsin, Amy. 2013. "Is Biology Destiny? Birth Weight and Differential Parental Treatment." Demography, Forthcoming.

Kaestner, Robert. 1997. "Are brothers really better? Sibling sex composition and educational achievement revisited." Journal of Human Resources, 32: 250-84.

Mash, E. J., and C. Johnston. 1983. "Sibling interactions of hyperactive and normal children and their relationship to reports of maternal stress and self-esteem." Journal of Clinical Child Psychology, 12: 91-99.

Meyer, D. J., and P. F. Vadasy. 2007. Sibshops: Workshops for siblings of children with special needs. Baltimore, MD: Paul H. Brookes.

Mikami, A.Y., and L. J. Pfiffner. 2008. "Sibling relationships among children with ADHD." Journal of Attention Disorders, 11(4): 482-492.

Milberger, S, J. Biederman, S. V. Faraone, T. Wilens, and M. P Chu. 1997. "Associations between ADHD and psychoactive substance use disorders: Findings from a longitudinal study of high-risk siblings of ADHD children." American Journal on Addictions, 6(4): 318-329.

Oettinger, Gerald S. 2000. "Sibling similarity in high school graduation outcomes: Causal interdependency or unobserved heterogeneity?" Southern Economic Journal, 66(3): 63148.

Opperman, S., and E. Alant. 2003. "The coping responses of the adolescent siblings of children with severe disabilities." Disability and Rehabilitation, 25(9): 441-454.

Ouyang, Lijing. 2004. "Sibling effects on teen risky behaviors." Duke University Working Paper.

Parish, S. L., and J. M. Cloud. 2006. "Financial well-being of young children with disabilities and their families." Social Work, 51(3): 223-232.

Pilowsky, T., N. Yirmiya, O. Doppelt, V. Gross-Tsur, and R. S. Shalev. 2004. "Social and emotional adjustment of siblings of children with autism." Journal of Child Psychology and Psychiatry, 45(4): 855-865.

Pitt, Mark M, Mark R Rosenzweig, and Md Nazmul Hassan. 1990. "Productivity, Health, and Inequality in the Intrahousehold Distribution of Food in Low-Income Countries." American Economic Review, 80(5): 1139-56.

Powers, E.T. 2004. "Children's health and maternal work activity: Estimates under alternative disability de?nitions." The Journal of Human Resources, 38(3): 522556.

Rosenzweig, Mark R., and Junsen Zhang. 2009. "Do Population Control Policies Induce More Human Capital Investment? Twins, Birth Weight and China's One-Child Policy." Review of Economic Studies, 76(3): 1149 - 1174. 
Rosenzweig, Mark R., and Kenneth I. Wolpin. 1988. "Heterogeneity, Intrafamily Distribution, and Child Health." Journal of Human Resources, 23(4): 437-461.

Rossiter, L., and D. (2001) Sharpe. 2001. "The siblings of individuals with mental retardation: A quantitative integration of the literature." Journal of Child and Family Studies, 10(1): 65-84.

SA, Russ, Larson K, and Halfon N. 2012. "A national profile of childhood epilepsy and seizure disorder." Pediatrics, 129(2): 256-64.

Sharpe, D., and L. Rossiter. 2002. "Siblings of children with a chronic illness: A metaanalysis." Journal of Pediatric Psychology, 27: 699710.

Siegel, Bryna, and Stuart Silverstein. 1994. What About Me? Growing Up with a Developmentally Disabled Sibling. Da Capo Press.

Smith, A. J., R. T. Brown, V. Bunke, R. L. Blount, and E. Christophersen. 2002. "Psychosicial adjustment and peer competence of siblings of children with attentiondeficit/hyperactivity disorder." Journal of Attention Disorders, 5(3): 165-177.

Stoneman, Z. 1998. "Handbook of Mental Retardation and Development." , ed. R. M. Hodapp \& E. Zigler J. A. Burack, Chapter Research on siblings of children with mental retardation: Contributions of developmental theory and etiology, 669692. Cambridge: Cambridge University Press.

Stoneman, Z. 2001. "Supporting positive sibling relationships during childhood." Ment Retard Dev Disabil Res Rev, 7: 134142.

Stoneman, Z. 2005. "Siblings of children with disabilities: research themes." Ment Retard, 43: 339350 .

Stoneman, Z., and G. H Brody. 1993. "The effects of mental retardation, disability, and illness on sibling relationships." , ed. Z. Stoneman \& P. W. Berman, Chapter Sibling relations in the family context, $3-30$. Baltimore: Brookes.

Widmer, Eric. 1997. "Influence of older siblings on initiation of sexual intercourse." Journal of Marriage and the Family, 59(4): 928-938.

Williams, Phoebe Dauz, Arthur R. Williams, J. Carolyn Graff, Sandra Hanson, Anne Stanton, Carol Hafeman, Adrienne Liebergen, Karla Leuenberg, Robyn Karlin Setter, Lavonne Ridder, Heather Curry, Martha Barnard, and Susan Sanders. 2002. "Interrelationships Among Variables Affecting Well Siblings and Mothers in Families of Children with a Chronic Illness or Disability." Journal of Behavioral Medicine, 25(5): $411-424$. 


\section{Tables}

Table 1: Demographic and Socioeconomic Characteristics Across THE FUll PSID-CDS AND THE Siblings AND COUSINS SUBSAMPleS

\begin{tabular}{|c|c|c|c|}
\hline & $\begin{array}{c}(1) \\
\text { PSID-CDS }\end{array}$ & $\begin{array}{c}(2) \\
\text { CDS Siblings }\end{array}$ & $\begin{array}{c}(3) \\
\text { CDS Cousins }\end{array}$ \\
\hline \multicolumn{4}{|l|}{ A. Basic Descriptive Data } \\
\hline Age & 9.79 & 9.68 & $10.0^{\ddagger}$ \\
\hline Male & 0.50 & 0.51 & 0.50 \\
\hline Black (non-Hisp.) & 0.16 & 0.15 & $0.20^{\dagger \ddagger}$ \\
\hline Hispanic & 0.13 & 0.14 & $0.05^{\dagger \dagger}$ \\
\hline Birth order & 2.03 & $2.14^{\dagger}$ & $2.20^{\dagger}$ \\
\hline PCG Education (=12 yrs) & 0.36 & 0.36 & 0.39 \\
\hline PCG Education (>12 yrs) & 0.49 & 0.48 & 0.50 \\
\hline Mother Age at Birth $(<20$ yrs $)$ & 0.08 & 0.08 & $0.10^{\dagger \ddagger}$ \\
\hline Mother Age at Birth ( $\geq 40$ yrs $)$ & 0.02 & $0.01^{\dagger}$ & $0.01^{\dagger}$ \\
\hline Urban (at birth) & 0.69 & 0.70 & 0.68 \\
\hline Mother Married at First Birth & 0.66 & 0.67 & 0.64 \\
\hline Family Income Prior to First Birth ${ }^{1}$ & 50,553 & 49,858 & 48,726 \\
\hline Mother's Family Poor & 0.29 & 0.28 & 0.27 \\
\hline Father's Family Poor & 0.33 & 0.33 & 0.31 \\
\hline Family Income $^{2}$ & 72,586 & 73,054 & 75,244 \\
\hline Two Biological Parents in $\mathrm{HH}$ & 0.65 & $0.69^{\dagger}$ & 0.67 \\
\hline Members of Family Unit & 4.36 & $4.70^{\dagger}$ & $4.69^{\dagger}$ \\
\hline \multicolumn{4}{|l|}{ B. Human Capital Outcomes } \\
\hline Grade Repetition & 0.119 & 0.109 & 0.121 \\
\hline WJ-R Applied Problems & 103.1 & 104.0 & 103.6 \\
\hline WJ-R Letter-Word & 102.5 & 102.6 & $101.1^{\dagger \ddagger}$ \\
\hline WJ-R Passage Comprehension & 101.9 & 102.1 & 101.6 \\
\hline \multicolumn{4}{|l|}{ C. Childhood Chronic Conditions } \\
\hline Developmental Disability & 0.048 & 0.045 & 0.049 \\
\hline Externalizing Behavior & 0.100 & 0.109 & 0.112 \\
\hline Low Birth Weight & 0.086 & 0.084 & $0.070^{\dagger \ddagger}$ \\
\hline Difficulty Hearing/Deaf & 0.029 & 0.030 & 0.029 \\
\hline Difficulty Seeing/Blind & 0.050 & 0.048 & 0.056 \\
\hline Emotional Disturbance & 0.030 & 0.031 & 0.036 \\
\hline Hyperactive/ADHD & 0.261 & 0.256 & 0.255 \\
\hline Dev. Delay/Learning Disab. & 0.082 & 0.077 & 0.085 \\
\hline Speech Impairment & 0.094 & 0.098 & $0.110^{\dagger}$ \\
\hline Heart Condition & 0.011 & 0.009 & 0.010 \\
\hline Diabetes & 0.004 & 0.004 & 0.004 \\
\hline Asthma & 0.164 & 0.159 & 0.164 \\
\hline Allergies & 0.176 & 0.166 & 0.168 \\
\hline
\end{tabular}

Notes: The full CDS sample includes 3,447 unique children with non-missing information on baseline demographic measures. The subsample of CDS sibling pairs consists of 2,206 unique children. The subsample of cousins includes 982 unique children from 209 distinct extended families. ${ }^{\dagger}$ Difference from full PSID-CDS statistically significant at $p=0.05$. ${ }^{\ddagger}$ Difference from CDS-Siblings statistically significant at $p=0.05$. Means weighted using sampling weights.

${ }^{1}$ Average income measured over five years prior to mother's first birth. ${ }^{2}$ Total family income averaged over previous five years. 


\begin{tabular}{|c|c|c|}
\hline \multirow[t]{2}{*}{ 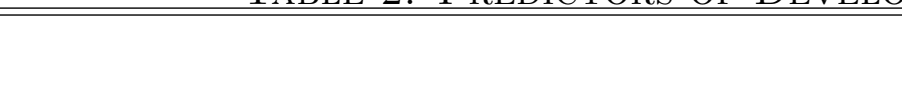 } & \multicolumn{2}{|c|}{ Probit } \\
\hline & dydx & $\mathrm{SE}$ \\
\hline Birth order & -0.000213 & $(0.00445)$ \\
\hline Male $^{(d)}$ & $0.0178^{* *}$ & $(0.00893)$ \\
\hline Black (non-Hisp.) $)^{(d)}$ & -0.0162 & $(0.0127)$ \\
\hline PCG Educ 12 years $^{(d)}$ & $-0.0284^{* *}$ & $(0.0119)$ \\
\hline PCG Educ $>12$ years $^{(d)}$ & $-0.0333^{* *}$ & $(0.0159)$ \\
\hline Family Income Prior to First Birth & $-0.0154^{* *}$ & $(0.00784)$ \\
\hline 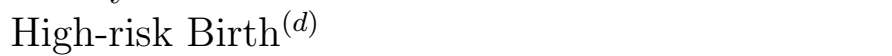 & -0.00664 & $(0.0145)$ \\
\hline Urban (at birth) ${ }^{(d)}$ & -0.000149 & $(0.00938)$ \\
\hline Mother Married at First $\operatorname{Birth}^{(d)}$ & $0.0263^{* *}$ & $(0.0123)$ \\
\hline Mother's Family Poor ${ }^{(d)}$ & -0.00945 & $(0.0102)$ \\
\hline Father's Family Poor ${ }^{(d)}$ & -0.0130 & $(0.0101)$ \\
\hline History Childhood Psych./Emotional Problems ${ }^{(d)}$ & 0.0510 & $(0.0574)$ \\
\hline $\operatorname{Catholic}^{(d)}$ & -0.00100 & $(0.0147)$ \\
\hline Protestant $^{(d)}$ & -0.0132 & $(0.0141)$ \\
\hline No Religion ${ }^{(d)}$ & -0.00489 & $(0.0191)$ \\
\hline Observations & 1277 & \\
\hline Log-likelihood Value & -186.6 & \\
\hline Pseudo $R^{2}$ & 0.058 & \\
\hline
\end{tabular}

Notes: Marginal effects estimated at sample means except in the case of binary $\operatorname{covariates}^{(d)}$, in which case marginal effects estimated as discrete change in dummy variable from 0 to 1 . Standard errors are in parentheses. Family Income averaged over five years prior to mother's first birth. High-risk birth measure is an indicator for births to mothers $<20$ years or $\geq 40$ years ${ }^{*} p<0.10,{ }^{* *} p<0.05$ 
TABle 3: Predictors of Externalizing BeHAVIOR

\begin{tabular}{|c|c|c|}
\hline & \multicolumn{2}{|c|}{ Probit } \\
\hline & dydx & SE \\
\hline Birth order & -0.000381 & $(0.00769)$ \\
\hline Male $\mathrm{M}^{(d)}$ & 0.0211 & $(0.0156)$ \\
\hline Black (non-Hisp.) ${ }^{(d)}$ & $-0.0391^{*}$ & $(0.0224)$ \\
\hline 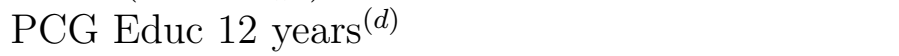 & -0.0310 & $(0.0218)$ \\
\hline PCG Educ > 12 years $^{(d)}$ & $-0.0681 * *$ & $(0.0254)$ \\
\hline Family Income Prior to First Birth & 0.00776 & $(0.0128)$ \\
\hline High-risk $\operatorname{Birth}^{(d)}$ & $0.0516^{*}$ & $(0.0297)$ \\
\hline Urban (at birth) ${ }^{(d)}$ & -0.0224 & $(0.0166)$ \\
\hline Mother Married at First $\operatorname{Birth}^{(d)}$ & -0.0387 & $(0.0240)$ \\
\hline Mother's Family Poor ${ }^{(d)}$ & 0.0317 & $(0.0213)$ \\
\hline Father's Family Poor ${ }^{(d)}$ & $-0.0346^{*}$ & $(0.0193)$ \\
\hline History Childhood Psych./Emotional Problems ${ }^{(d)}$ & $0.192^{* *}$ & $(0.0850)$ \\
\hline $\operatorname{Catholic}^{(d)}$ & 0.0338 & $(0.0356)$ \\
\hline $\operatorname{Protestant}^{(d)}$ & 0.0503 & $(0.0322)$ \\
\hline No Religiom $^{(d)}$ & $0.113^{*}$ & $(0.0677)$ \\
\hline Observations & 1264 & \\
\hline Log-likelihood Value & -381.6 & \\
\hline Pseudo $R^{2}$ & 0.079 & \\
\hline
\end{tabular}

Notes: Marginal effects estimated at sample means except in the case of binary $\operatorname{covariates}^{(d)}$, in which case marginal effects estimated as discrete change in dummy variable from 0 to 1 . Standard errors are in parentheses. Family Income averaged over five years prior to mother's first birth. High-risk birth measure is an indicator for births to mothers $<20$ years or $\geq 40$ years ${ }^{*} p<0.10,{ }^{* *} p<0.05$ 
Table 4: Effects of Poor Health on Human Capital Accumulation

\begin{tabular}{|c|c|c|c|c|c|c|}
\hline & $\begin{array}{r}\text { ( } \\
\text { Bas } \\
\text { Con }\end{array}$ & $\begin{array}{l}\text { 1) } \\
\text { eline } \\
\text { trols }\end{array}$ & $\begin{array}{r}\text { Full } \\
\text { Co }\end{array}$ & $\begin{array}{l}\text { 2) } \\
\text { amily } \\
\text { trols }\end{array}$ & $\begin{array}{r}\text { Base } \\
\text { Me }\end{array}$ & $\begin{array}{l}\text { 3) } \\
\text { atorcl. } \\
\text { ators }\end{array}$ \\
\hline & \multicolumn{4}{|c|}{ A. Developmental Disabilities } & & \\
\hline & Own & Sibling & Own & Sibling & Own & Sibling \\
\hline \multirow[t]{2}{*}{ Grade Repetition } & $0.0700^{* *}$ & $0.0476^{*}$ & 0.0214 & 0.0043 & $0.0680^{* *}$ & 0.0458 \\
\hline & $(0.0316)$ & $(0.0287)$ & $(0.0277)$ & $(0.0278)$ & $(0.0314)$ & $(0.0286)$ \\
\hline WJ-R Applied & $\begin{array}{c}-9.297^{* *} \\
(1.988)\end{array}$ & $\begin{array}{c}-4.169^{* *} \\
(1.632)\end{array}$ & $\begin{array}{c}-7.786^{* *} \\
(2.324)\end{array}$ & $\begin{array}{c}-4.417^{* *} \\
(2.206)\end{array}$ & $\begin{array}{c}-8.697^{* *} * \\
(1.955)\end{array}$ & $\begin{array}{c}-3.628^{* *} * \\
(1.631)\end{array}$ \\
\hline WJ-R Letter & $\begin{array}{c}-6.936^{* *} \\
(1.936)\end{array}$ & $\begin{array}{c}-5.777^{* *} \\
(1.765)\end{array}$ & $\begin{array}{c}-3.858^{*} \\
(2.200)\end{array}$ & $\begin{array}{c}-5.082^{* *} \\
(2.340)\end{array}$ & $\begin{array}{c}-6.449^{* *} \\
(1.916)\end{array}$ & $\begin{array}{c}-5.348^{* *} \\
(1.783)\end{array}$ \\
\hline \multirow[t]{3}{*}{ WJ-R Passage } & $\begin{array}{c}-5.770^{* * *} \\
(1.861)\end{array}$ & $\begin{array}{c}-3.795^{* *} \\
(1.623)\end{array}$ & $\begin{array}{c}-4.413^{* * *} \\
(2.065)\end{array}$ & $\begin{array}{l}-3.579^{*} \\
(2.103)\end{array}$ & $\begin{array}{c}-5.285^{* *} \\
(1.833)\end{array}$ & $\begin{array}{c}-3.289^{* * *} \\
(1.625)\end{array}$ \\
\hline & & B. Extern & lizing Bel & avior & & \\
\hline & Own & Sibling & Own & Sibling & Own & Sibling \\
\hline Grade Repetition & $\begin{array}{l}0.150^{* *} \\
(0.0248)\end{array}$ & $\begin{array}{l}0.0349^{*} \\
(0.0201)\end{array}$ & $\begin{array}{l}0.149^{* *} \\
(0.0308)\end{array}$ & $\begin{array}{c}0.0580^{* *} \\
(0.0266)\end{array}$ & $\begin{array}{l}0.146^{* *} \\
(0.0251)\end{array}$ & $\begin{array}{c}0.0314 \\
(0.0209)\end{array}$ \\
\hline WJ-R Applied & $\begin{array}{c}-6.381^{* *} \\
(1.026)\end{array}$ & $\begin{array}{c}-3.791^{* *} \\
(0.970)\end{array}$ & $\begin{array}{c}-5.612^{* *} \\
(1.211)\end{array}$ & $\begin{array}{c}-2.571^{* *} \\
(1.200)\end{array}$ & $\begin{array}{c}-5.809^{* * *} \\
(1.026)\end{array}$ & $\begin{array}{c}-3.439^{* * *} \\
(0.958)\end{array}$ \\
\hline WJ-R Letter & $\begin{array}{c}-6.700^{* *} \\
(1.201)\end{array}$ & $\begin{array}{c}-3.569^{* *} \\
(1.089)\end{array}$ & $\begin{array}{c}-4.992^{* *} \\
(1.489)\end{array}$ & $\begin{array}{c}-2.781^{* *} \\
(1.315)\end{array}$ & $\begin{array}{c}-6.026^{* *} \\
(1.243)\end{array}$ & $\begin{array}{c}-3.026^{* *} \\
(1.087)\end{array}$ \\
\hline WJ-R Passage & $\begin{array}{c}-6.718^{* *} \\
(1.092)\end{array}$ & $\begin{array}{c}-1.931^{* *} \\
(0.914)\end{array}$ & $\begin{array}{c}-5.200^{* *} \\
(1.318)\end{array}$ & $\begin{array}{l}-1.220 \\
(1.127)\end{array}$ & $\begin{array}{c}-5.803^{* *} \\
(1.133)\end{array}$ & $\begin{array}{l}-1.151 \\
(0.913)\end{array}$ \\
\hline
\end{tabular}

Notes: Standard errors in parentheses are robust to within-family correlation. Baseline correlation.

Baseline controls include wave indicators, age, gender, race, maternal education, birth order, and high-risk birth. Expanded or "Full" family controls additionally include mother's marital status at time of first birth, urbancity at time of birth, parental family background (poor, not poor), average average family income prior to birth of first child, parental history of childhood psychological or emotional problems, and primary caregiver's religion. Potential family mediators include family income, family size, and family structure. To be included in the regression sample, a sibling pair must satisfy one of three conditions: the target child has condition of interest, the sibling has the condition of interest, or both members of the pair are healthy.

${ }^{*} p<0.10,{ }^{* *} p<0.05$ 


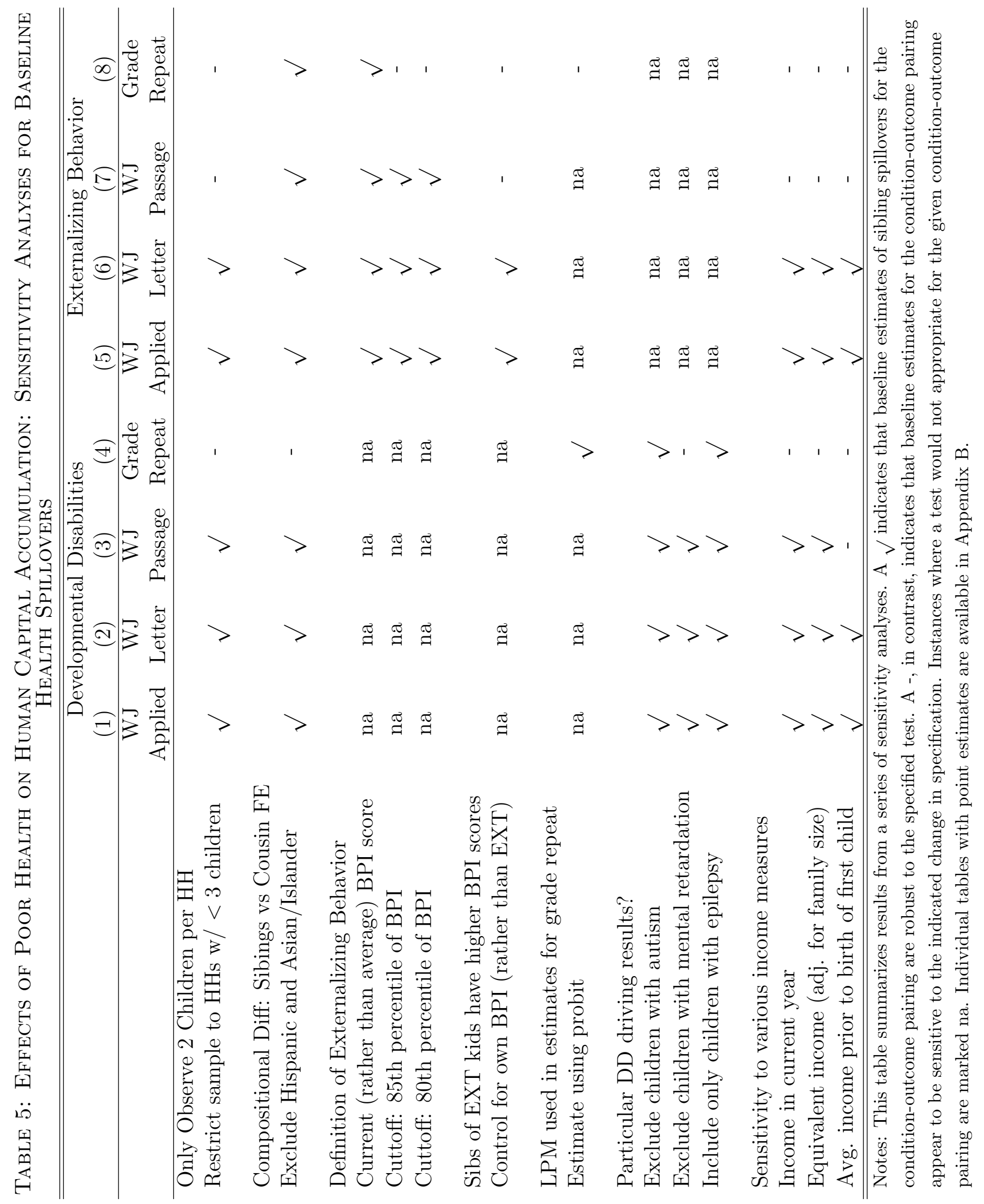




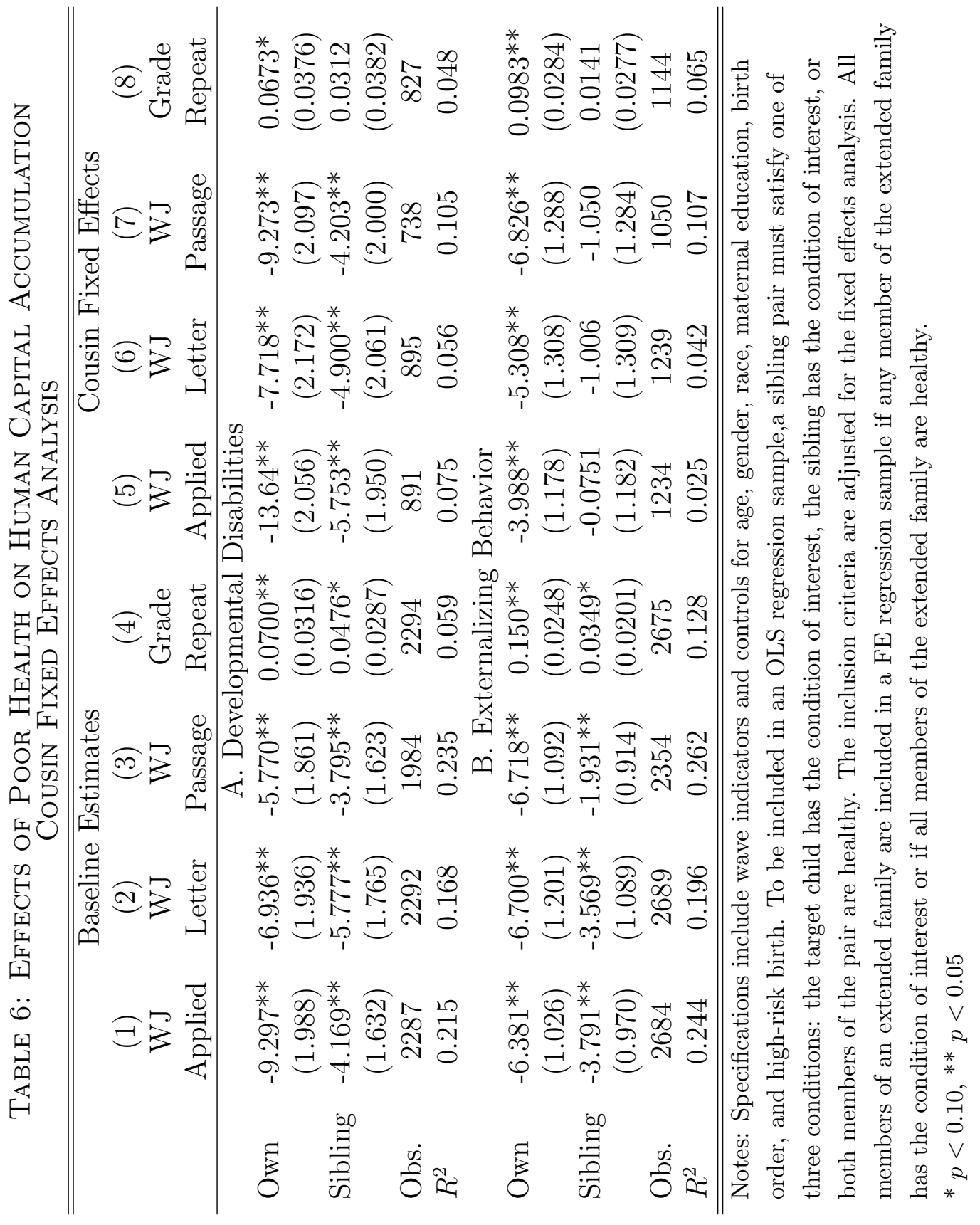


Table 7: Effects of Poor Health on Human Capital Accumulation

\begin{tabular}{|c|c|c|c|c|c|c|}
\hline & \multicolumn{3}{|c|}{ Heterogeneity by Gender } & \multicolumn{3}{|c|}{ "Heterogeneity by Relative Age } \\
\hline & Males & Females & Difference & Older & Younger & Difference \\
\hline & \multicolumn{6}{|c|}{ A. Developmental Disability } \\
\hline \multirow[t]{2}{*}{ WJ Applied } & 0.757 & $-7.845^{* *}$ & $8.602^{* *}$ & $-4.539^{*}$ & -3.343 & -1.577 \\
\hline & $(2.058)$ & $(2.288)$ & $(3.048)$ & $(2.340)$ & $(2.262)$ & $(3.254)$ \\
\hline \multirow{2}{*}{ WJ Letter } & -3.028 & $-8.047^{* *}$ & 5.019 & $-5.757 * *$ & $-5.395 * *$ & -0.968 \\
\hline & $(2.628)$ & $(2.185)$ & $(3.377)$ & $(2.800)$ & $(1.993)$ & $(3.417)$ \\
\hline \multirow[t]{2}{*}{ WJ Passage } & -0.855 & $-6.034^{* *}$ & 5.179 & -2.335 & $-4.866^{* *}$ & 2.198 \\
\hline & $(2.390)$ & $(2.094)$ & $(3.171)$ & $(1.515)$ & $(1.195)$ & $(2.009)$ \\
\hline \multirow[t]{3}{*}{ Grade Repeat } & 0.0113 & $0.0815^{*}$ & -0.0702 & $(2.415)$ & $(2.124)$ & $(3.192)$ \\
\hline & $(0.0365)$ & $(0.0425)$ & $(0.0554)$ & 0.0110 & $0.0850^{* *}$ & -0.0635 \\
\hline & \multicolumn{6}{|c|}{ B. Externalizing Behavior } \\
\hline \multirow[t]{2}{*}{ WJ Applied } & $-2.902^{*}$ & $-4.299 * *$ & 1.397 & $-2.351^{*}$ & $-5.292^{* *}$ & 2.939 \\
\hline & $(1.508)$ & $(1.314)$ & $(2.056)$ & $(1.420)$ & $(1.449)$ & $(2.120)$ \\
\hline \multirow[t]{2}{*}{ WJ Letter } & -2.586 & $-4.304^{* *}$ & 1.719 & -0.807 & $-6.143^{* *}$ & $5.336 * *$ \\
\hline & $(1.661)$ & $(1.497)$ & $(2.280)$ & $(1.579)$ & $(1.626)$ & $(2.385)$ \\
\hline \multirow[t]{2}{*}{ WJ Passage } & -1.356 & $-2.129^{*}$ & 0.773 & 0.118 & $-4.024^{* *}$ & $4.155^{*}$ \\
\hline & 0.0445 & 0.0191 & 0.0254 & $(1.455)$ & $(1.392)$ & $(2.168)$ \\
\hline \multirow[t]{2}{*}{ Grade Repeat } & $(0.0322)$ & $(0.0237)$ & $(0.0396)$ & 0.0192 & $0.0482^{*}$ & -0.0258 \\
\hline & $(0.0380)$ & $(0.0431)$ & $(0.0569)$ & $(0.0280)$ & $(0.0282)$ & $(0.0398)$ \\
\hline
\end{tabular}

Notes: Specifications include wave indicators and controls for age, gender, race, maternal education, birth order, and high-risk birth. To be included in the regression sample,a sibling pair must satisfy one of three conditions: the targetchild has the condition of interest, the sibling has the condition of interest, or both members of the pair are healthy.Standard errors in parentheses are robust to within-family correlation.

${ }^{*} p<0.10,{ }^{* *} p<0.05$ 


\section{Appendix}

\section{A}

Consider a household with two children indexed $\mathrm{i}=\mathrm{H}, \mathrm{L}$. Sibling $\mathrm{H}$ is healthy with high endowment $e_{H}$. Sibling $\mathrm{L}$, who has a chronic illness, experiences an early-life shock and has low endowment $e_{L}=e_{H}+\mu$. Assume that the human capital of children is produced according to a CES technology and is affected by endowment and parental investment:

$$
h_{i}=\left[\gamma e_{i}^{\phi}+(1-\gamma) i_{H}^{\phi}\right]^{\frac{1}{\phi}}
$$

Assume that parents are altruistic and care about the quality (human capital accumulation) of their children as well as their own consumption. Following Behrman, Pollak, and Taubman (1982), further assume that the utility parents derive from their own consumption is separable from the utility they derive from children, so that we may analyze the allocations of resources across siblings without regard to its effects on parental consumption. Parental preferences are specified by a CES utility function:

$$
U=\left[a h_{H}^{\rho}+(1-a) h_{L}^{\rho}\right]^{\frac{1}{\rho}}
$$

where the parameter a allows for the possibility that parents favor the human capital formation of one particular child - according to gender, birth order, etc. - over the other. Parents maximize utility subject to the human capital production technology and the partial budget constraint:

$$
i_{H}+i_{L}=\bar{y}
$$

where $\bar{y}$ is the total value of parental resources allocated to the children.

Setting the marginal utilities from investment equal across children: 


$$
\frac{\partial U}{\partial h_{H}} \frac{\partial h_{H}}{\partial i_{H}}=\frac{\partial U}{\partial h_{L}} \frac{\partial h_{L}}{\partial i_{L}}
$$

$$
a\left[\gamma e_{H}^{\phi}+(1-\gamma) i_{H}^{\phi}\right]^{\frac{\rho-\phi}{\phi}}=(1-a)\left[\gamma\left(e_{H}+\mu\right)^{\phi}+(1-\gamma)\left(\bar{y}-i_{H}\right)^{\phi}\right]^{\frac{\rho-\phi}{\phi}}\left(\bar{y}-i_{H}\right)^{\phi-1}
$$

We define $G\left(\mu, i_{H}\right)$ :

$$
\begin{aligned}
G\left(\mu, i_{H}\right) & =a\left[\gamma e_{H}^{\phi}+(1-\gamma) i_{H}^{\phi}\right]^{\frac{\rho-\phi}{\phi}} \\
& -(1-a)\left[\gamma\left(e_{H}+\mu\right)^{\phi}+(1-\gamma)\left(\bar{y}-i_{H}\right)^{\phi}\right]^{\frac{\rho-\phi}{\phi}}\left(\bar{y}-i_{H}\right)^{\phi-1}
\end{aligned}
$$

Then by the implicit function theorem, the cross effect of the shock to sibiling L's endowment on investment in healthy sibling $\mathrm{H}$ may be written:

$$
\frac{\partial i_{H}}{\partial \mu}=\frac{-\partial G / \partial \mu}{\partial G / \partial i_{H}}
$$

Whether parents optimally adopt a reinforcing, compensating or neutral strategy in response to the differences in their children's endowments will depend on two paremeters: the complementarity (substitutability) of endowments and investments in the human capital technology $(\phi)$ and the aversion to inequality in parental preferences $(\rho)$. The direction of the optimal investment strategy is independent of the degree of favor for child $\mathrm{H}$ in the parental preferences (a).

The cross effect on sibling H's human capital may be written:

$$
\frac{\partial h_{H}}{\partial \mu}=\frac{\partial h_{H}}{\partial i_{H}} \frac{\partial i_{H}}{\partial \mu}
$$

If parents adopt a compensating strategy such that $\frac{\partial i_{H}}{\partial \mu}>0\left(i_{H}\right.$ and $\mu$ move in the same direction), $\frac{\partial h_{H}}{\partial \mu}>0$ and the human capital formation of healthy sibling suffers. If parents 
adopt a reinforcing strategy, however, $\frac{\partial h_{H}}{\partial \mu}<0$. Healthy sibling $\mathrm{H}$ benefits from increased parental investment and, ultimately, increased human capital formation.

In the above model, a sibling's early-life health insult may affect child outcomes through the reallocation of intrahousehold resources. The model precludes any direct effect operating through the human capital technology. In reality, we may expect a sibling's chronic health condition (diminished endowment) to directly influence child outcomes through several channels, including social learning (eg conformity, imitation, learning spillovers) and disruptions to the learning environment. We extend the above model by introducing sibling endowment as a thrid factor in the human capital technology:

$$
h_{i}=\left[\gamma e_{i}^{\phi}+\lambda e_{j}^{\phi}+(1-\gamma-\lambda) i_{H}^{\phi}\right]^{\frac{1}{\phi}}
$$

Parental preferences and the budget constraint are left unaltered. Again, we set the marginal utilities from investment equal across children:

$a\left[\gamma e_{H}^{\phi}+\lambda\left(e_{H}+\mu\right)^{\phi}+(1-\gamma-\lambda) i_{H}^{\phi}\right]^{\frac{\rho-\phi}{\phi}}=(1-a)\left[\gamma\left(e_{H}+\mu\right)^{\phi}+\lambda e_{H}^{\phi}+(1-\gamma-\lambda)\left(\bar{y}-i_{H}\right)^{\phi}\right]^{\frac{\rho-\phi}{\phi}}\left(\bar{y}-i_{H}\right)^{\phi-1}$

We define $G\left(\mu, i_{H}\right)$ :

$$
\begin{aligned}
G\left(\mu, i_{H}\right) & =a\left[\gamma e_{H}^{\phi}+\lambda\left(e_{H}+\mu\right)^{\phi}+(1-\gamma-\lambda) i_{H}^{\phi}\right]^{\frac{\rho-\phi}{\phi}} \\
& -(1-a)\left[\gamma\left(e_{H}+\mu\right)^{\phi}+\lambda e_{H}^{\phi}+(1-\gamma-\lambda)\left(\bar{y}-i_{H}\right)^{\phi}\right]^{\frac{\rho-\phi}{\phi}}\left(\bar{y}-i_{H}\right)^{\phi-1}
\end{aligned}
$$

The cross effect of the shock to sibiling L's endowment on investment in healthy sibling H may be written:

$$
\frac{\partial i_{H}}{\partial \mu}=\frac{-\partial G / \partial \mu}{\partial G / \partial i_{H}}
$$

Now, whether parents optimally adopt a reinforcing, compensating or neutral strategy in 
response to the differences in their children's endowments will hinge on the the complementarity (substitutability) of endowments and investments in the human capital technology $(\phi)$, along with the aversion to inequality $(\rho)$ and degree of favor for child $\mathrm{H}(\mathrm{a})$ in the parental preferences.

The effect on the human capital of child $\mathrm{H}$ may be decomposed into two channels:

$$
\frac{\partial h_{H}}{\partial \mu}=\frac{\partial h_{H}}{\partial e_{L}} \frac{\partial e_{L}}{\partial \mu}+\frac{\partial h_{H}}{\partial i_{H}} \frac{\partial i_{H}}{\partial \mu}
$$

The first channel represents the direct or social learning effect. The term $\frac{\partial h_{H}}{\partial e_{L}} \frac{\partial e_{L}}{\partial \mu}$ is positive, which is consistent with a deterimental influence on $h_{H}$ (the shock $\mu$ is negative). The second channel represents the resource reallocation effect. If parents adopt a compensating or neutral strategy such that $\frac{\partial i_{H}}{\partial \mu} \geq 0\left(i_{H}\right.$ and the $\mu$ move in the same direction), $\frac{\partial h_{H}}{\partial i_{H}} \frac{\partial i_{H}}{\partial \mu}>0$ and the human capital formation of healthy sibling H suffers. If parents adopt a reinforcing investment strategy such that $\frac{\partial i_{H}}{\partial \mu}<0$ ( $i_{H}$ and the $\mu$ move in opposite directions), $\frac{\partial h_{H}}{\partial i_{H}} \frac{\partial i_{H}}{\partial \mu}<0$. The net effect on human capital will be ambiguous, depending on the relative magnitudes of the social learning and resource reallocation effects. 
B

Table B.1: Developmental Disability in the CDS-Siblings Sample

(3)

CDS-Siblings Males Females

\begin{tabular}{lccc}
\hline Autism & 0.285 & 0.378 & 0.151 \\
Epilepsy & 0.689 & 0.570 & 0.867 \\
Mental Retardation & 0.219 & 0.222 & 0.215 \\
& & & \\
Single Disability & 0.833 & 0.830 & 0.839 \\
Multiple Disabilities & 0.167 & 0.170 & 0.161 \\
\hline \hline
\end{tabular}

A child is classified as developmentally disabled if he/she has ever been diagnosed with epilepsy, autism, or mental retardation. There are 228 observations (95 unique children) with DD in the CDS-

Siblings sample. Of those observations, 135 correspond to males and 93 correspond to females. 


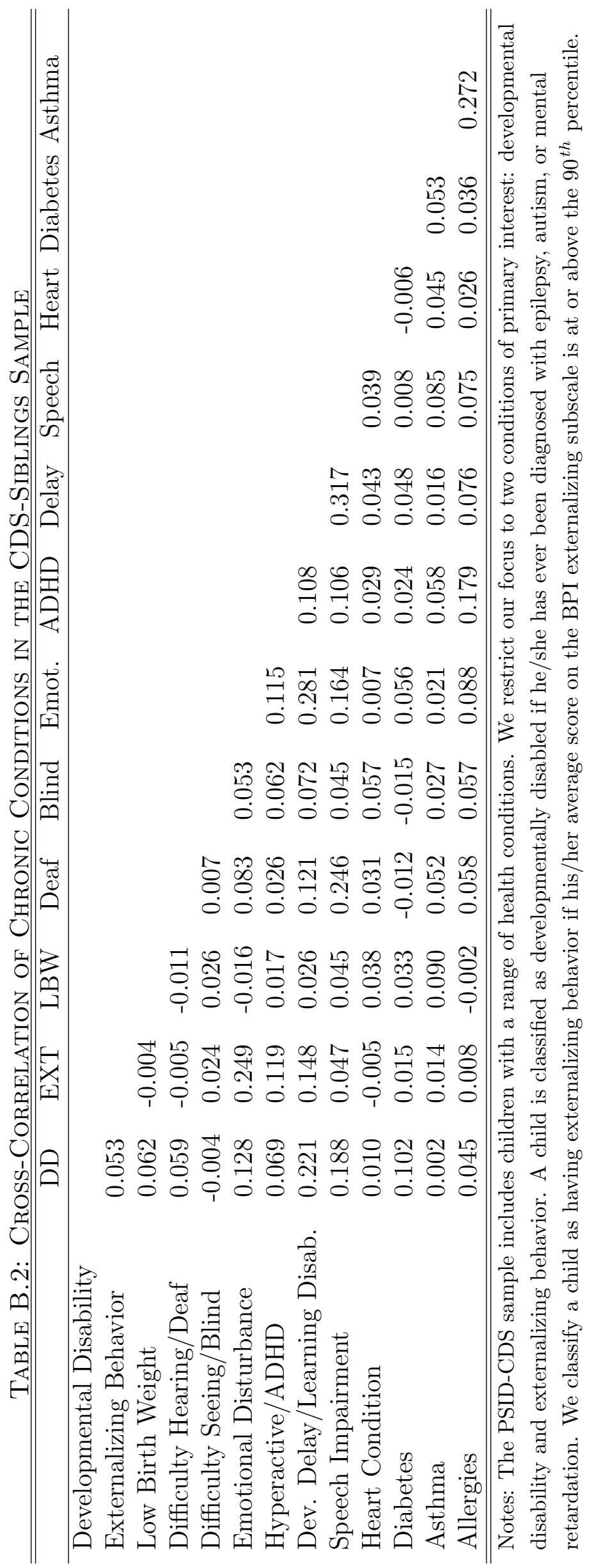


TABle B.3: Correlation of Chronic Conditions Within Families

(1)

Sibling Pair ${ }^{\dagger} \quad$ Extended Family ${ }^{\ddagger}$

\begin{tabular}{lcccc} 
& DD & EXT & DD & EXT \\
\hline Developmental Disability & 0.066 & & -0.020 & -0.056 \\
Externalizing Behavior & 0.037 & 0.149 & -0.043 & -0.022 \\
& & & & \\
Low Birth Weight & 0.035 & 0.020 & -0.017 & 0.018 \\
Difficulty Hearing/Deaf & 0.051 & 0.058 & 0.024 & -0.015 \\
Difficulty Seeing/Blind & 0.037 & 0.033 & 0.011 & 0.044 \\
Emotional Disturbance & 0.089 & 0.087 & -0.004 & -0.003 \\
Hyperactive/ADHD & 0.046 & 0.091 & 0.065 & 0.061 \\
Dev. Delay/Learning Disab. & 0.052 & 0.050 & 0.021 & 0.030 \\
Speech Impairment & 0.093 & 0.035 & 0.055 & -0.019 \\
Heart Condition & -0.019 & 0.031 & -0.011 & 0.065 \\
Diabetes & 0.020 & 0.081 & -0.038 & -0.064 \\
Asthma & 0.060 & 0.032 & 0.014 & 0.045 \\
Allergies & 0.022 & 0.020 & 0.040 & -0.033 \\
\hline \hline
\end{tabular}

Notes: ${ }^{\dagger}$ Correlation between own developmental disability (DD) or externalizing behavior (EXT) and various indicators of sibling health status. ${ }^{\ddagger}$ Correlation between own developmental disability (DD) or externalizing behavior (EXT) and various indicators of extended family health status - at least one CDS cousin has been diagnosed with the specified chronic condition. 
TAble B.4: Distribution of Scores on the BPI Externalizing Subscale

\begin{tabular}{|c|c|c|c|c|c|c|c|c|}
\hline $\begin{array}{c}(1) \\
\mathrm{n}\end{array}$ & $\begin{array}{c}(2) \\
\text { Min }\end{array}$ & $\begin{array}{c}(3) \\
\operatorname{Max}\end{array}$ & $\begin{array}{c}(4) \\
\text { Mean }\end{array}$ & $\begin{array}{c}(5) \\
10^{t h}\end{array}$ & $\begin{array}{c}(6) \\
25^{t h}\end{array}$ & $\begin{array}{c}(7) \\
50^{t h}\end{array}$ & $\begin{array}{c}(8) \\
75^{\text {th }}\end{array}$ & $\begin{array}{c}(9) \\
90^{t h}\end{array}$ \\
\hline \multicolumn{9}{|c|}{ PSID-CDS Sample } \\
\hline 9,828 & 0 & 17 & 5.56 & 1.33 & 2.67 & 5 & 8 & 10.67 \\
\hline \multicolumn{9}{|c|}{ CDS-Siblings Sample } \\
\hline 5,038 & 0 & 17 & 5.56 & 1 & 2.66 & 5 & 8 & 11 \\
\hline \multicolumn{9}{|c|}{ Diagnosed ADHD/Hyperactivity } \\
\hline 382 & 0 & 16.5 & 9.42 & 4 & 7 & 10 & 12 & 14 \\
\hline \multicolumn{9}{|c|}{ Developmental Disability } \\
\hline 228 & 0 & 16 & 7.24 & 2.67 & 5 & 7 & 10.3 & 11.5 \\
\hline \multicolumn{9}{|c|}{ Externalizing Behavior ${ }^{\dagger}$} \\
\hline 549 & 10.67 & 17 & 12.4 & 11 & 11.3 & 12 & 13 & 14.3 \\
\hline \multicolumn{9}{|c|}{ Sibling w/ Developmental Disability } \\
\hline 226 & 0 & 15 & 6.37 & 1.33 & 3 & 6.25 & 9.33 & 11.5 \\
\hline \multicolumn{9}{|c|}{ Sibling w/ Externalizing Behavior } \\
\hline 551 & 0 & 17 & 7.63 & 2.67 & 4.5 & 7.5 & 10.5 & 12 \\
\hline
\end{tabular}

Notes: ${ }^{\dagger}$ By definition, the average BPI Externalizing score for a child classified as having externalizing behavior must be at or above the $90^{\text {th }}$ percentile (score of 10.67). 


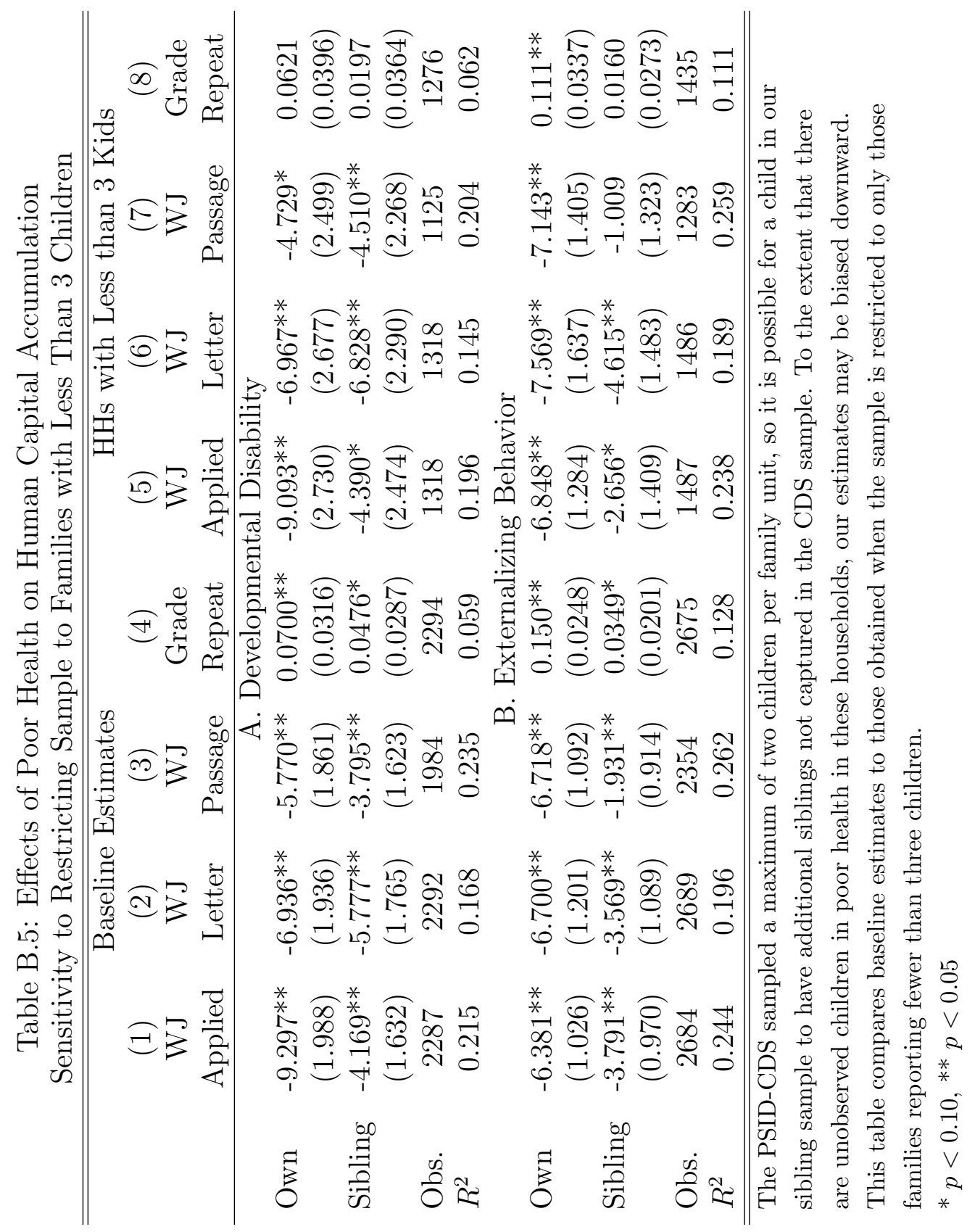




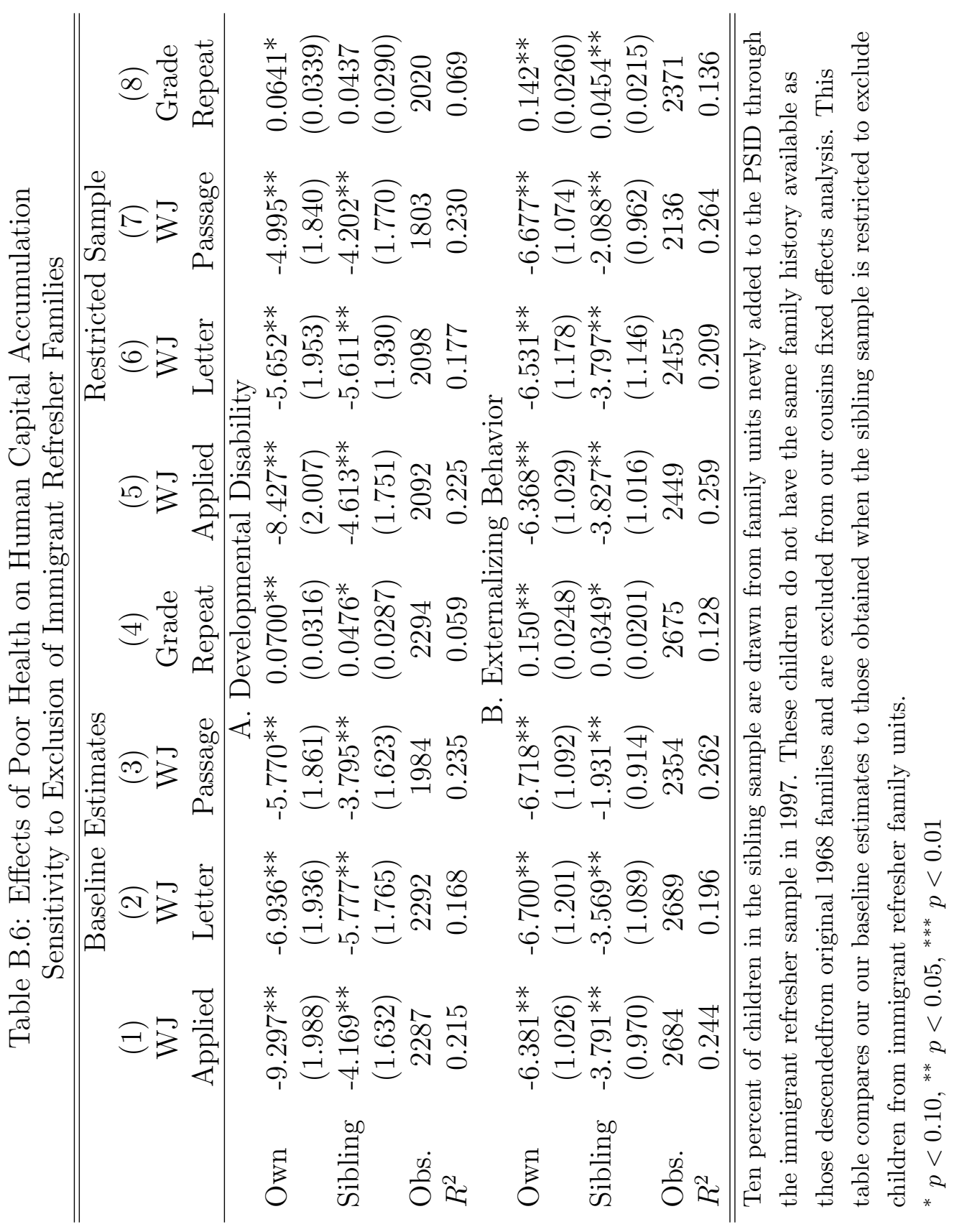




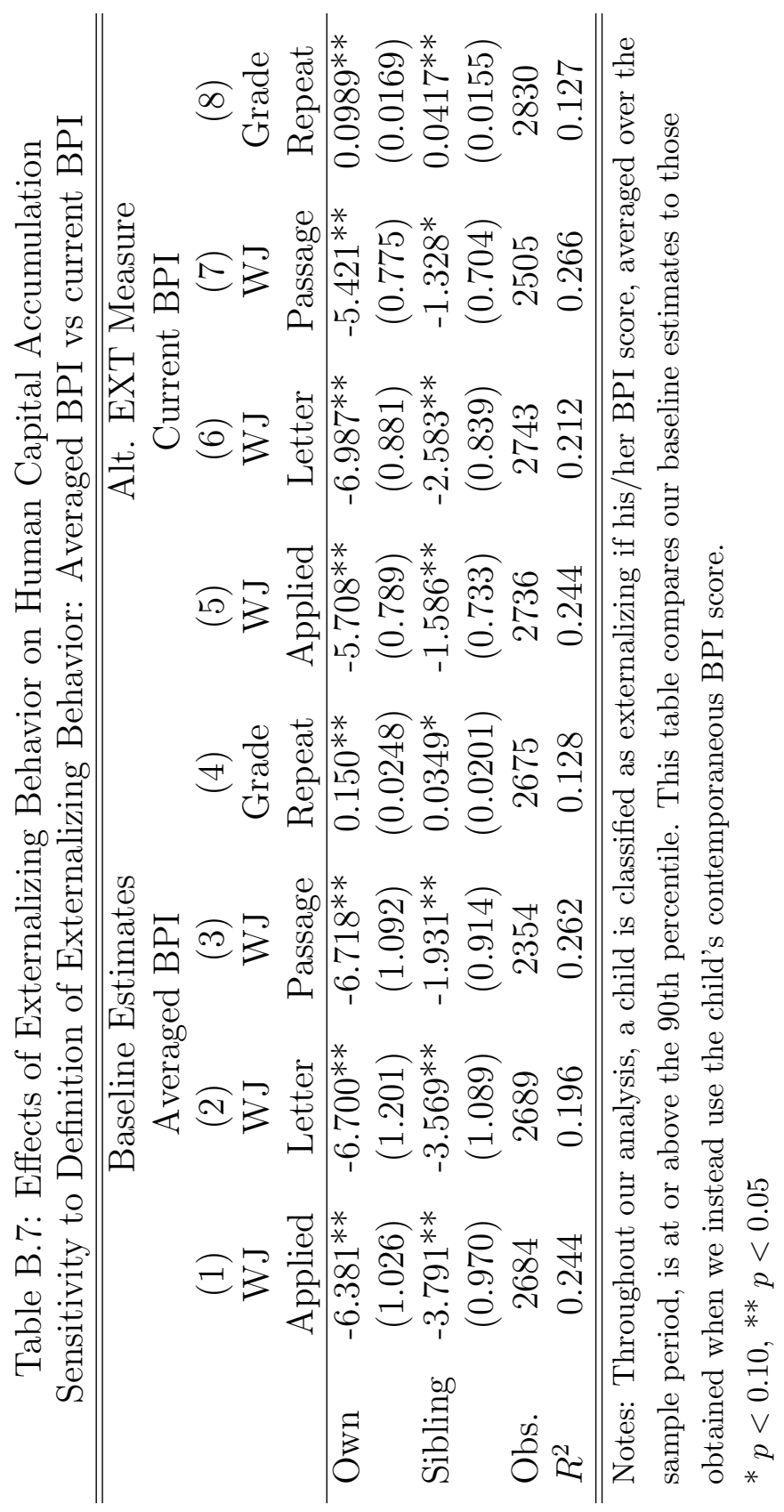




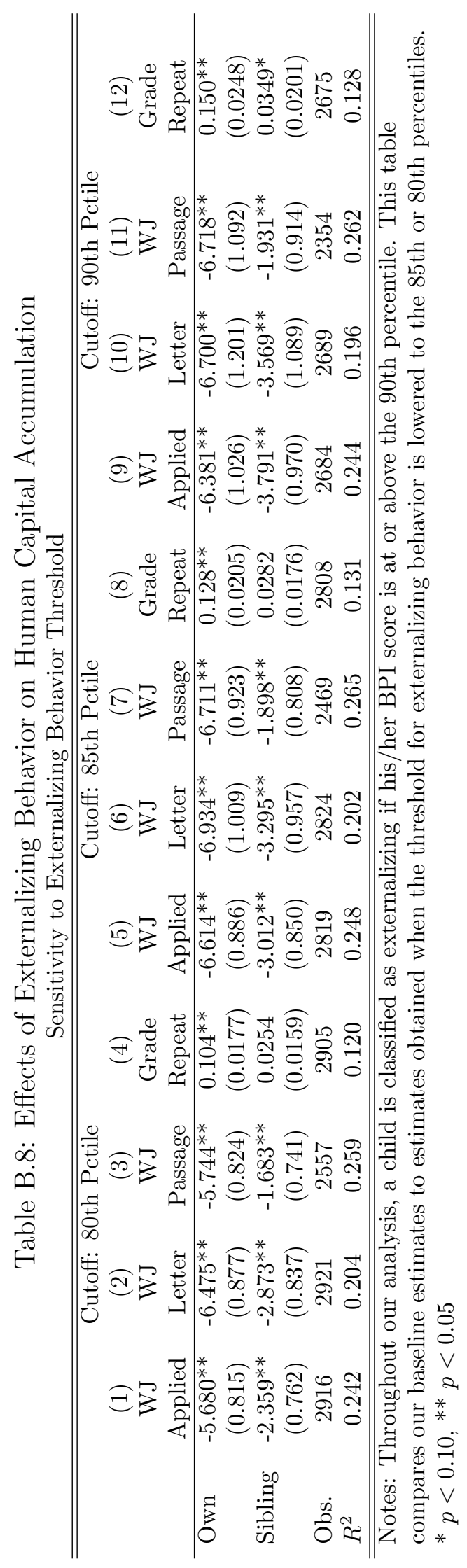




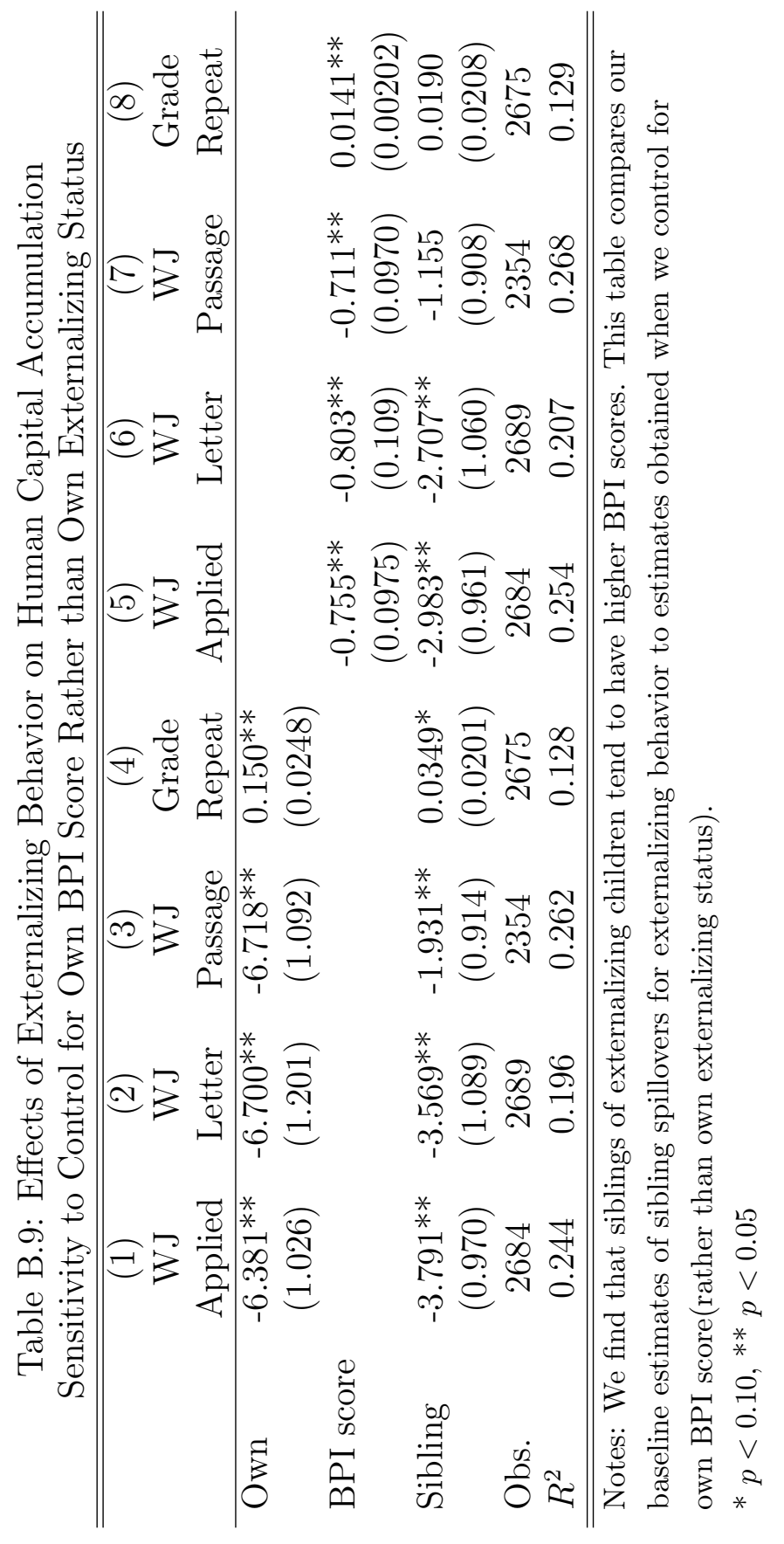


Table B.10: Effects of Poor Health on Human Capital Accumulation Sensitivity of Grade Repeat Estimates to Probit Specification

\begin{tabular}{lcccc}
\hline \hline & \multicolumn{2}{c}{ Developmental Disability } & \multicolumn{2}{c}{ Externalizing Behavior } \\
& $(1)$ & $(2)$ & $(3)$ & $(4)$ \\
& Grade Repeat & Grade Repeat & Grade Repeat & Grade Repeat \\
& LPM & Probit dydx & LPM & Probit dydx \\
\hline Own & $0.0700^{* *}$ & $0.0732^{* *}$ & $0.150^{* *}$ & $0.126^{* *}$ \\
& $(0.0316)$ & $(0.0323)$ & $(0.0248)$ & $(0.0238)$ \\
Sibling & $0.0476^{*}$ & $0.0500^{*}$ & $0.0349^{*}$ & 0.0233 \\
& $(0.0287)$ & $(0.0300)$ & $(0.0201)$ & $(0.0156)$ \\
Observations & 2294 & 2294 & 2675 & 2675 \\
$R^{2}$ & 0.059 & 0.110 & 0.128 & 0.187 \\
\hline \hline
\end{tabular}

Notes: In the case of grade repetition, a binary outcome measure, we use a linear probability model to obtain our baseline estimates of sibling health spillovers. This table compares our baseline LPM estimates to the marginal effects from a probit.

${ }^{*} p<0.10,{ }^{* *} p<0.05$ 


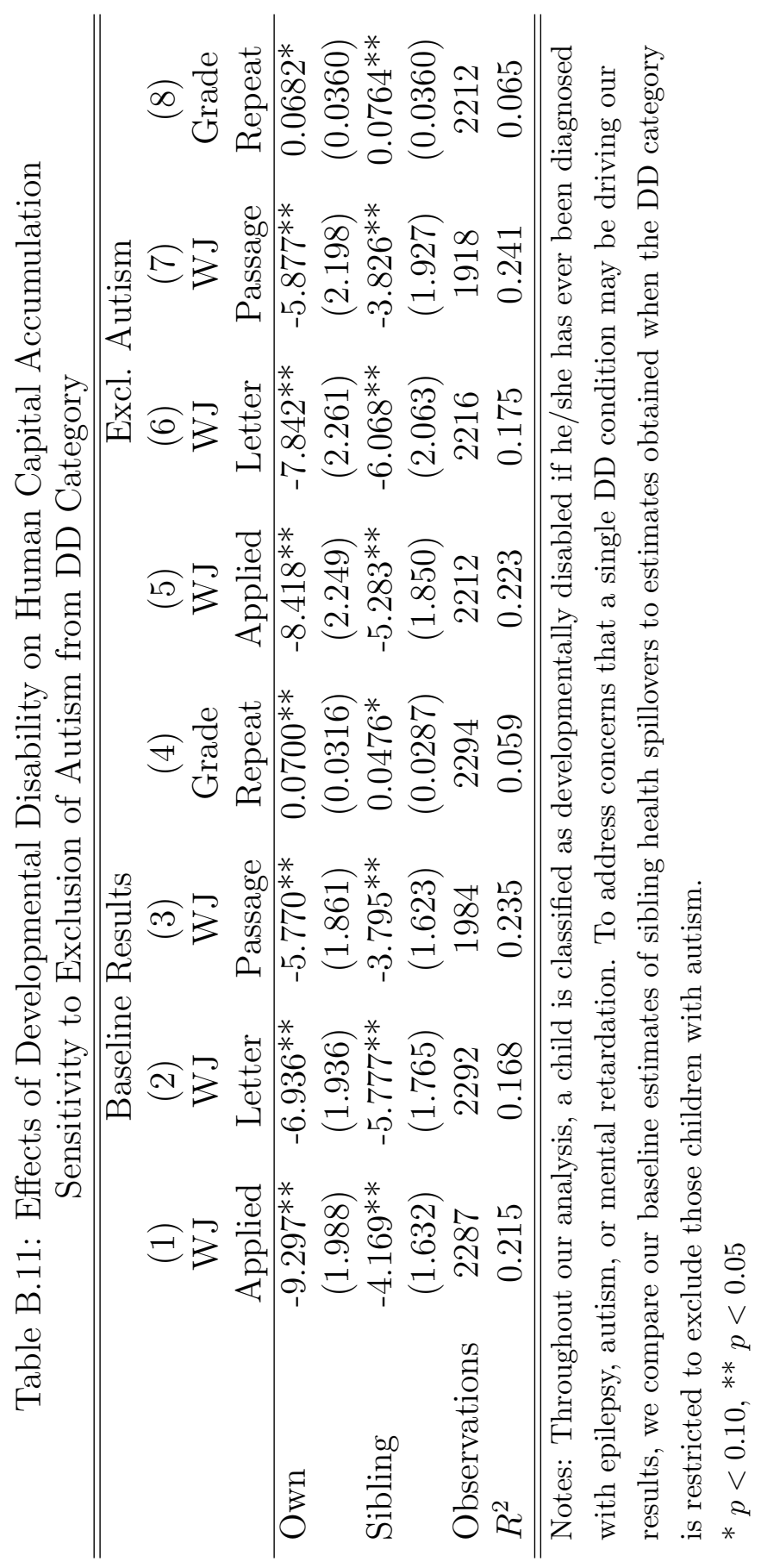




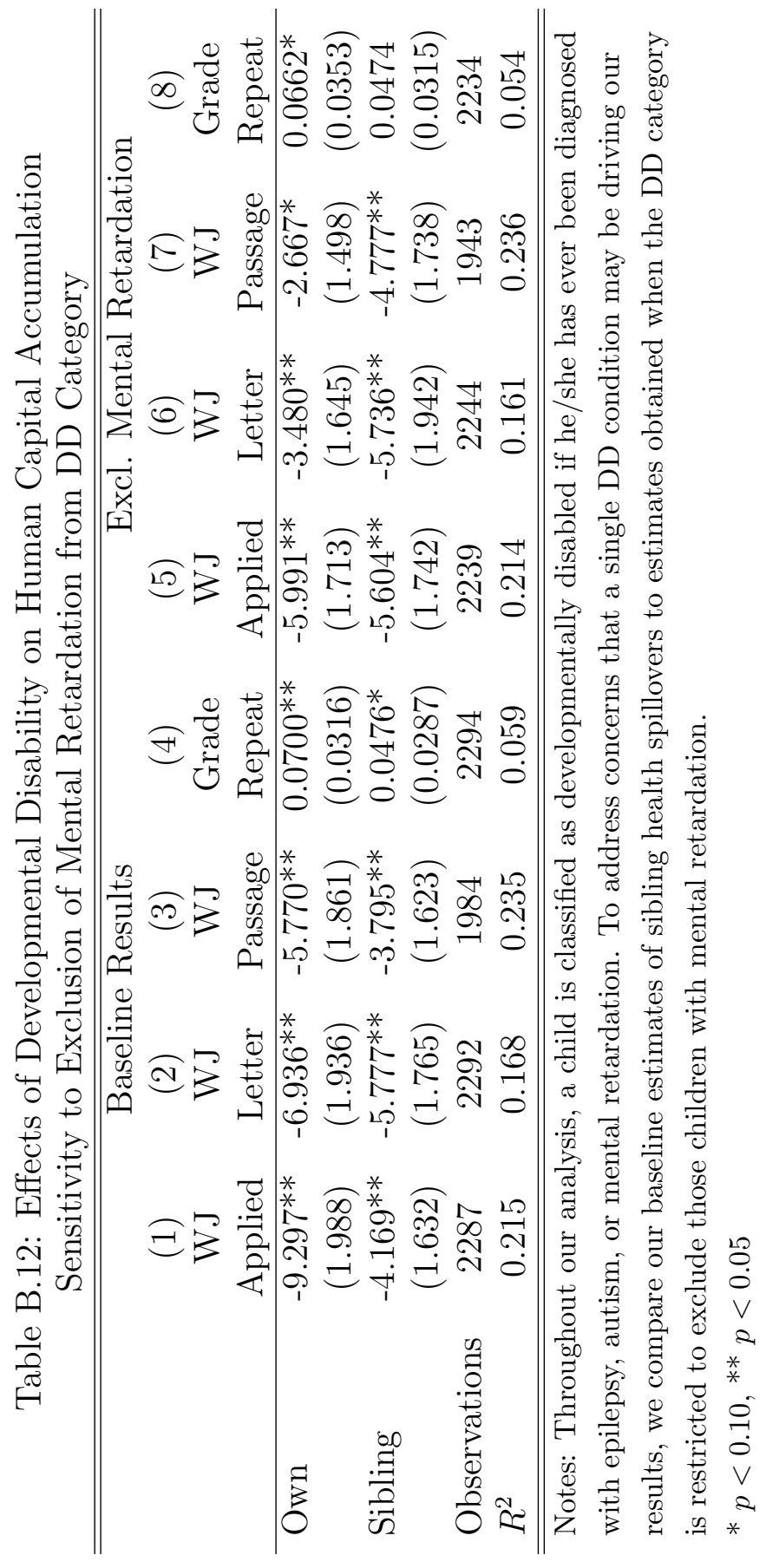




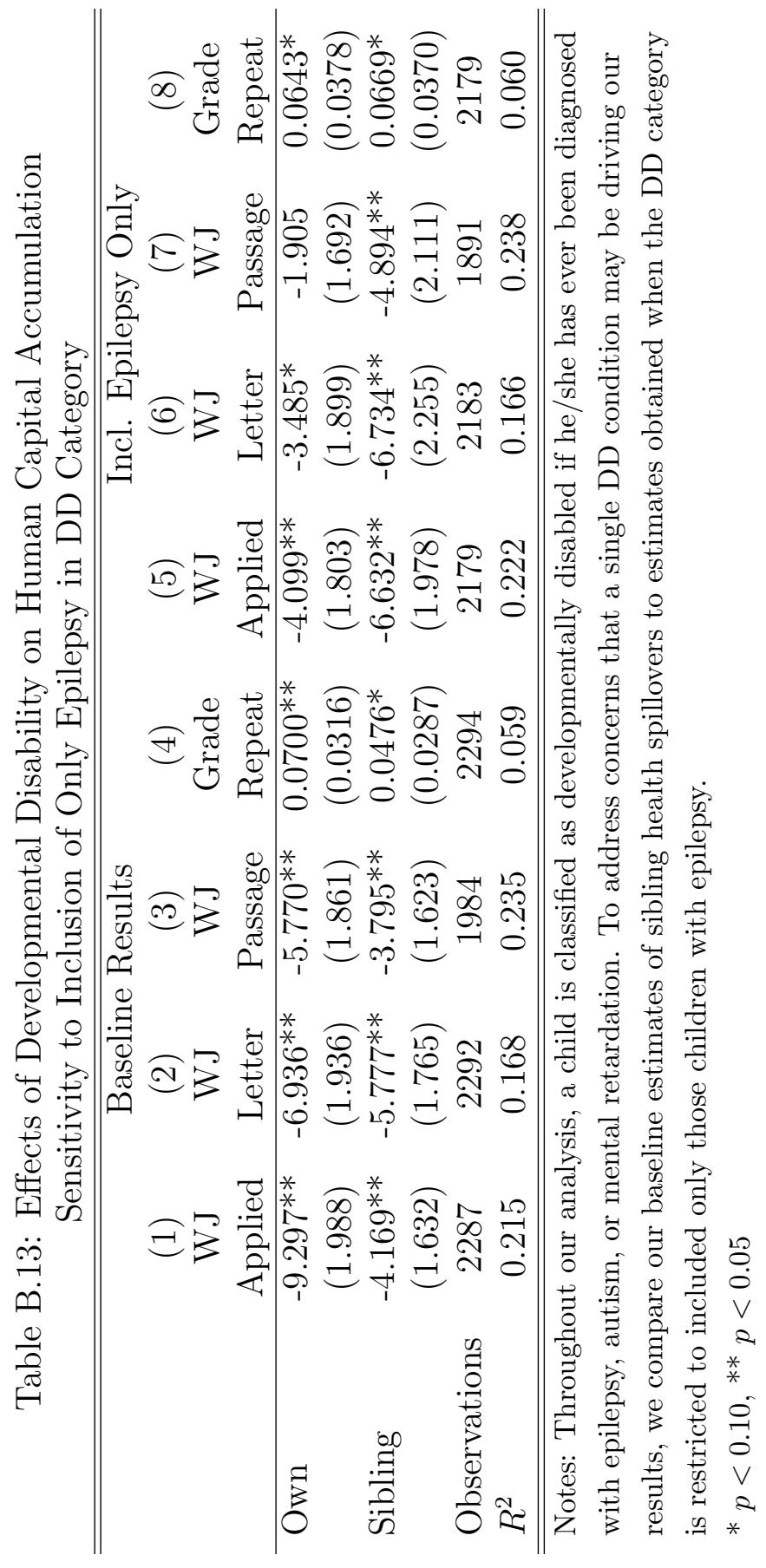


Table B.14: Effects of Poor Health on Human Capital Accumulation Sensitivity to Alternate Income Measures

\begin{tabular}{|c|c|c|c|c|c|c|c|c|}
\hline & \multicolumn{4}{|c|}{ Developmental Disability } & \multicolumn{4}{|c|}{ Externalizing Behavior } \\
\hline & $(1)$ & $(2)$ & $(3)$ & $(4)$ & $(5)$ & $(6)$ & $(7)$ & $(8)$ \\
\hline & WJ & WJ & WJ & Grade & WJ & WJ & WJ & Grade \\
\hline & Applied & Letter & Passage & Repeat & Applied & Letter & Passage & Repeat \\
\hline & \multicolumn{8}{|c|}{ A. Baseline Estimates: 5yr Rolling Average } \\
\hline Own & $\begin{array}{c}-8.697^{* *} \\
(1.955)\end{array}$ & $\begin{array}{c}-6.449^{* *} \\
(1.916)\end{array}$ & $\begin{array}{c}-5.285^{* *} \\
(1.833)\end{array}$ & $\begin{array}{c}0.0680^{* *} \\
(0.0314)\end{array}$ & $\begin{array}{c}-5.809^{* *} \\
(1.026)\end{array}$ & $\begin{array}{c}-6.026^{* *} \\
(1.243)\end{array}$ & $\begin{array}{c}-5.803^{* *} \\
(1.133)\end{array}$ & $\begin{array}{l}0.146^{* *} \\
(0.0251)\end{array}$ \\
\hline Sibling & $\begin{array}{c}-3.628^{* *} \\
(1.631)\end{array}$ & $\begin{array}{c}-5.348^{* *} \\
(1.783)\end{array}$ & $\begin{array}{c}-3.289^{* *} \\
(1.625)\end{array}$ & $\begin{array}{c}0.0458 \\
(0.0286)\end{array}$ & $\begin{array}{c}-3.439 * * \\
(0.958)\end{array}$ & $\begin{array}{c}-3.026^{* *} \\
(1.087)\end{array}$ & $\begin{array}{l}-1.151 \\
(0.913)\end{array}$ & $\begin{array}{c}0.0314 \\
(0.0209)\end{array}$ \\
\hline Obs. & 2281 & 2286 & 1979 & 2287 & 2670 & 2676 & 2341 & 2661 \\
\hline$R^{2}$ & & 0.175 & 0.251 & 0.062 & 0.259 & 0.207 & 0.281 & 0.132 \\
\hline & \multicolumn{8}{|c|}{ B. 5yr Rolling Average Adjusted for Family Size } \\
\hline Own & & $\begin{array}{c}-6.438^{* *} \\
(1.912)\end{array}$ & $\begin{array}{c}-5.279^{* *} \\
(1.832)\end{array}$ & $\begin{array}{c}0.0679^{* *} \\
(0.0314)\end{array}$ & $\begin{array}{c}-5.799^{* *} \\
(1.025)\end{array}$ & $\begin{array}{c}-6.013^{* *} \\
(1.242)\end{array}$ & $\begin{array}{c}-5.798^{* *} \\
(1.133)\end{array}$ & \\
\hline Sibling & $\begin{array}{c}-3.612^{* *} \\
(1.632)\end{array}$ & $\begin{array}{c}-5.328^{* *} \\
(1.785)\end{array}$ & $\begin{array}{c}-3.281^{* *} \\
(1.626)\end{array}$ & $\begin{array}{r}0.0 \\
(0.0\end{array}$ & $\begin{array}{r}-3.44 \\
(0.9 !\end{array}$ & $\begin{array}{c}-3.029^{* *} \\
(1.086)\end{array}$ & $\begin{array}{l}-1.151 \\
(0.913)\end{array}$ & $\begin{array}{c}0.0313 \\
(0.0209)\end{array}$ \\
\hline Obs. & 281 & 2286 & 1979 & 2287 & 2670 & 2676 & 2341 & 2661 \\
\hline$R^{2}$ & 0.228 & 0.175 & 0.251 & 0.062 & 0.259 & 0.207 & 0.281 & 0.132 \\
\hline & \multicolumn{8}{|c|}{ C. Measured Prior to Mother's First Birth } \\
\hline Own & $\begin{array}{l}358^{* *} \\
.119)\end{array}$ & $\begin{array}{c}-3.657^{*} \\
(1.979)\end{array}$ & $\begin{array}{c}-3.828^{* *} \\
(1.932)\end{array}$ & $\begin{array}{c}0.0446 \\
(0.0333)\end{array}$ & $\begin{array}{c}-5.153^{* *} \\
(1.051)\end{array}$ & $\begin{array}{c}-4.789^{* *} \\
(1.225)\end{array}$ & $\begin{array}{c}-4.947^{* *} \\
(1.102)\end{array}$ & $\begin{array}{c}0.132^{* *} \\
(0.0277)\end{array}$ \\
\hline Sibling & $\begin{array}{c}-3.780^{* *} \\
(1.855)\end{array}$ & $\begin{array}{c}-3.938^{*} \\
(2.053)\end{array}$ & $\begin{array}{l}-2.938 \\
(1.901)\end{array}$ & $\begin{array}{c}0.0261 \\
(0.0306)\end{array}$ & $\begin{array}{c}-2.884^{* *} \\
(1.063)\end{array}$ & $\begin{array}{c}-2.655^{* *} \\
(1.147)\end{array}$ & $\begin{array}{l}-0.970 \\
(1.021)\end{array}$ & $\begin{array}{c}0.0266 \\
(0.0233)\end{array}$ \\
\hline Obs. & 802 & 1808 & 1548 & 1739 & 2156 & 2163 & 1878 & 2080 \\
\hline$R^{2}$ & 227 & 0.176 & 0.242 & 0.071 & 0.252 & 0.211 & 0.275 & 0.132 \\
\hline & \multicolumn{8}{|c|}{ D. Measured in Current Year } \\
\hline Own & $\begin{array}{c}-8.784^{* *} \\
(1.950)\end{array}$ & $\begin{array}{c}-6.457^{* *} \\
(1.894)\end{array}$ & $\begin{array}{c}-5.202^{* *} \\
(1.805)\end{array}$ & $\begin{array}{c}0.0677^{* *} \\
(0.0312)\end{array}$ & $\begin{array}{c}-5.794^{* *} \\
(1.022)\end{array}$ & $\begin{array}{c}-5.968^{* *} \\
(1.242)\end{array}$ & $\begin{array}{c}-5.760^{* *} \\
(1.134)\end{array}$ & $\begin{array}{c}0.146^{* *} \\
(0.0250)\end{array}$ \\
\hline Sibling & $\begin{array}{c}-3.724^{* *} \\
(1.626)\end{array}$ & $\begin{array}{c}-5.359^{* *} \\
(1.778)\end{array}$ & $\begin{array}{c}-3.221^{* *} \\
(1.618)\end{array}$ & $\begin{array}{c}0.0453 \\
(0.0283)\end{array}$ & $\begin{array}{c}-3.480^{* *} \\
(0.966)\end{array}$ & $\begin{array}{c}-3.028^{* *} \\
(1.093)\end{array}$ & $\begin{array}{l}-1.136 \\
(0.920)\end{array}$ & $\begin{array}{c}0.0312 \\
(0.0209)\end{array}$ \\
\hline Obs. & 2281 & 2286 & 1979 & 2287 & 2670 & 2676 & 2341 & 2661 \\
\hline$R^{2}$ & 0.224 & 0.175 & 0.256 & 0.063 & 0.251 & 0.203 & 0.279 & 0.132 \\
\hline
\end{tabular}

Notes: In baseline specifications family income is measured as a five-year average up to and including the current year/wave. This table compares estimates of sibling health spillovers across specifications with various controls for family income. In panel B family income is again measured as a five-year average, but family income is additionally adjusted for family size. In panel $\mathrm{C}$ family income is measured as an average over the five years prior to the birth of the first child. Finally, in panel D we measure family income in the current year/wave.

${ }^{*} p<0.10,{ }^{* *} p<0.05$ 